Salwa Gerges SALMAN ${ }^{1}$ \& Muhammad Abbas HAYAS ${ }^{2}$

\title{
THE AESTHETICS OF PLACE IN THE ALCHEMIST'S NOVEL FOR PAULO COELHO
}

\section{Istanbul / Türkiye}

\section{p. $40-51$}

\section{Article Information}

Article Type: Research Article

This article was checked by

iThenticate No plagiarism

detected

\section{Article History}

Received: $22 / 01 / 2021$

Accepted: $08 / 02 / 2021$

published: $01 / 03 / 2021$

\section{Abstract:}

This paper aims to identify the aesthetic characteristics of the element of place in the novel (The Alchemist) through the process of influence, being affected, and revealing contradictions that existing in the human community.

The plan involves an introduction and two chapters. The introduction came in two axes: the first: the place, linguistically and idiomatically, and the second axis: the summary of the novel. Whereas the first chapter, which is labeled (types of place), is based on four topics:

- The first: the domesticated place - the non-domesticated place.

- The second: the open space - the closed place

- Third: Place of residence - place of relocation

- Fourth: the real place - the imaginary place

Moreover, the second chapter entitled (Description), it included three sections:

- The first: the relationship of place to the character.

- The second: the relationship of the place to the event.

- The third: the relationship of the character to the event.

At the end we conclude the conclusion of the paper with the most important results.

Key words: Paulo Coelho, The Alchemist, Novel.

http://dx.doi.org/10.47832/2791-9323.1-2.3

1 it

Dr. , Kirkuk University, Iraq, salwajarjis@gmail.com, https://orcid.org/0000-0002-1555-6103

2 Researcher, Iraq 


\section{جماليات المكان في "رواية الخيميائي" لـ (باولو كويلو)}

\section{سلوى جرجيس سلمان 3 \\ محمد عباس هياس4}

\section{الملخص المنان}

سعى البحث إلى الوقوف على الخصائص الجمالية لعنصر المكان في رواية (الخيميائي) من خلال عملية التأثير والتأثر والكشف عن التناقضات القائمة في المجتمع الإلى الإنساني. وقد قامت الخطة على تمهيد وفصلين، جاء التمهيد في محورين: الأول: المكان لغة واصطات المطلاحا، والمحور الثاني: ملخص الرواية. في حين نهض الفصل الأول الموسوم ب(أنواع المكان) على مباحث أربعة: الأول: المكان الأليف - المكان غير الأليف (المعادي)

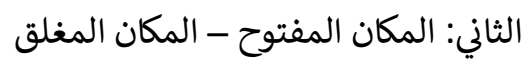

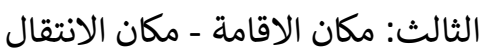
الرابع: المكان الواقعي - المكان المانة - مكان الانقال المتخيل

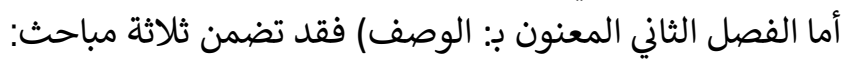

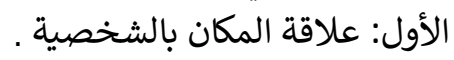

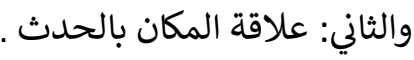
والثالث: علاقة الشخصية بالحدث الثماث.

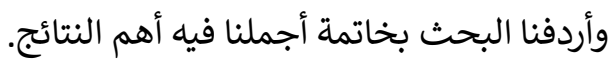
الكلمات المفتاحية: باولو كويلو، جماليات المكان، روائة أنمانية الخيميائي.

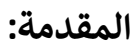

يتيح العمل الروائي تصوير المكان بحرفية بحيث يصبح للمكان جمالية خاصة يميزها القارئ وأيضا يصبح المكان قادر المار

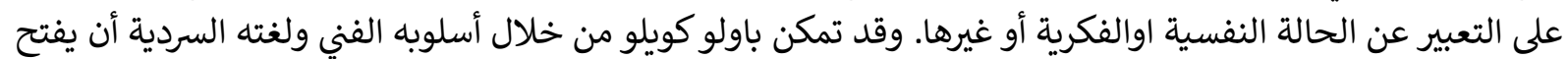

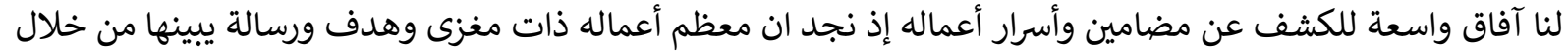

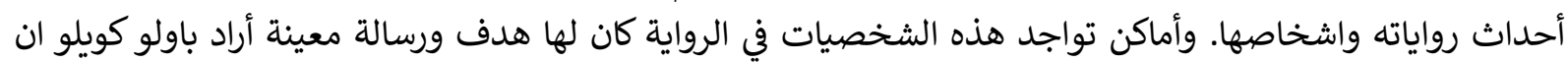

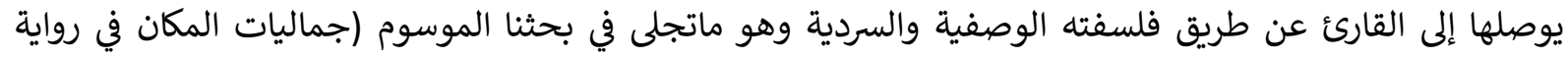

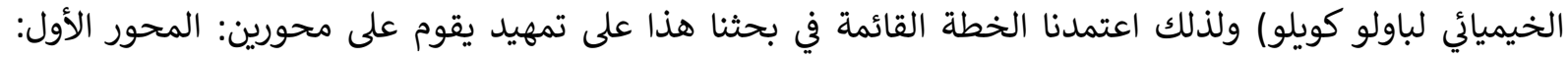
تعريف المكان لغة واصطلاحا، المحور الثاني جاء فيه ملخص للرواية وتضمن فيلمن فصلين:

الفصل الأول: أنواع المكان (التقاطبات المكانية):

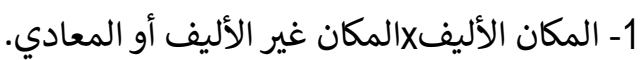

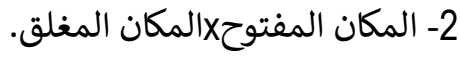

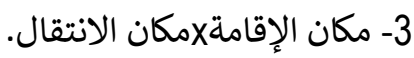

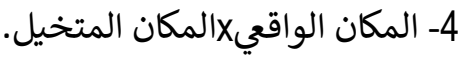
أما الفصل الثاني: وصف المكان المكان:

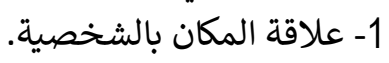

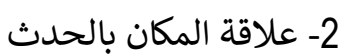


وأن أكثر المصادر التي اعتمدنا عليها وتكرر ذكرها في بحثنا:

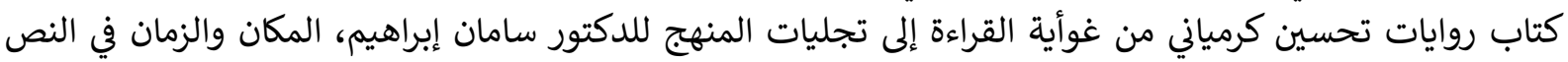

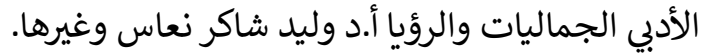

جاء في القاموس المحيط ان المكان: الموضع كالمكانة ج: أمكنة وأماكن (الفيروزآبادي،لبنان،1228،2005).وكذلك أورد

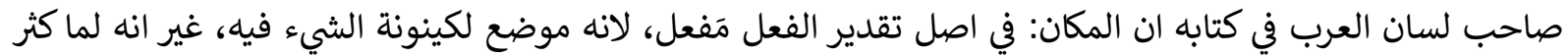

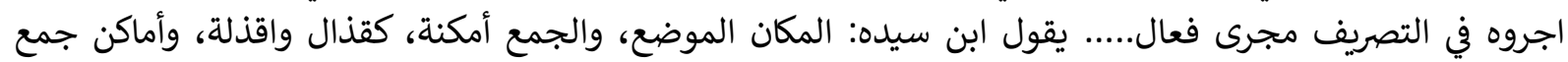

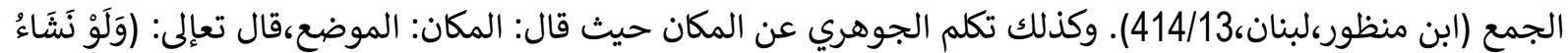

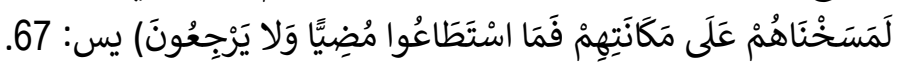

المكان اصطلاحا

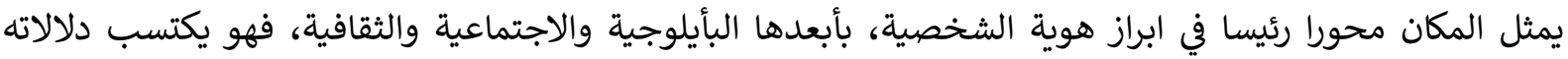

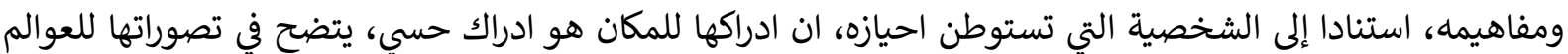

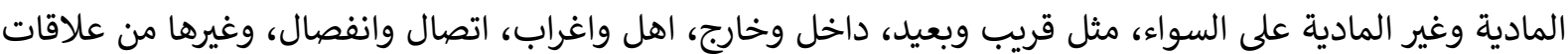

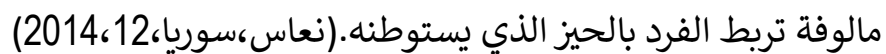

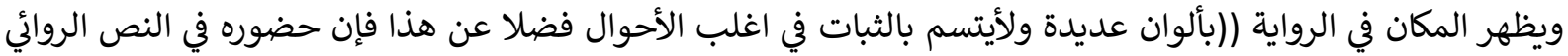

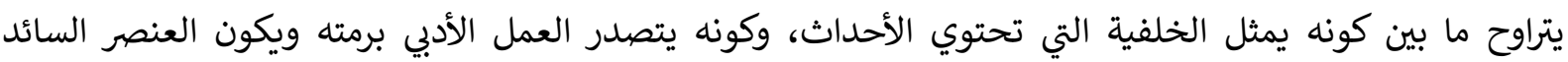

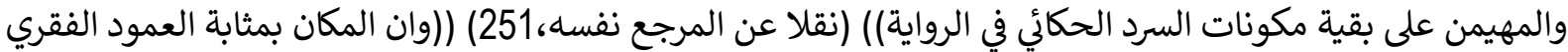

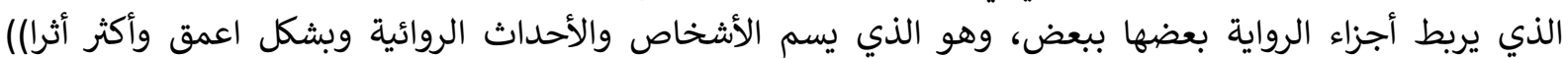

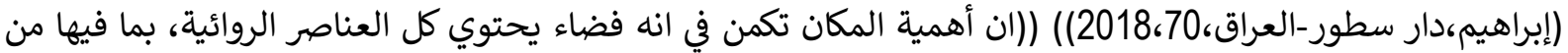

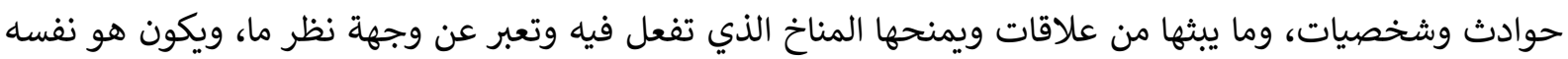

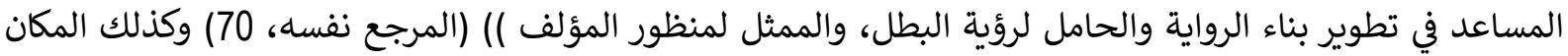

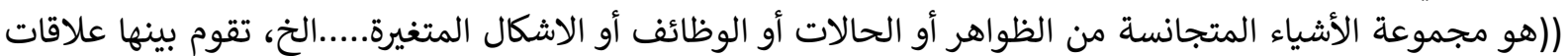

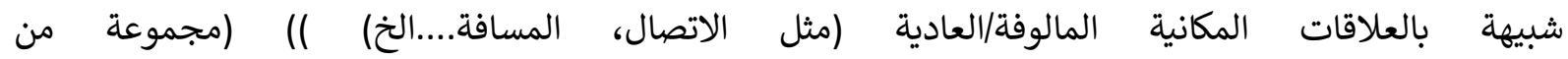

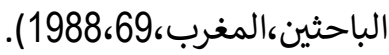

\section{ملخص الرواية}

تدور أحداث الرواية حول سانتياغو الفتى الاسباني الذي يبدأ يومه راكضا وراء قطيع الأغنام حاملا كتابا يقرؤه في أوقات

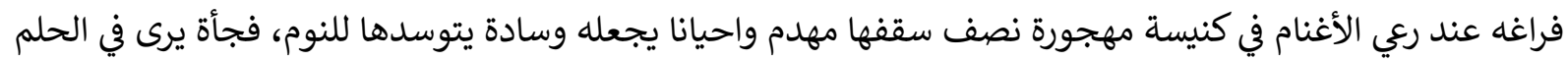

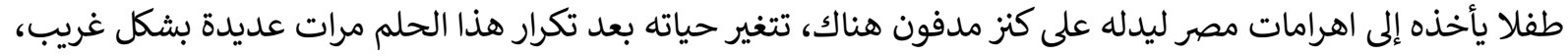

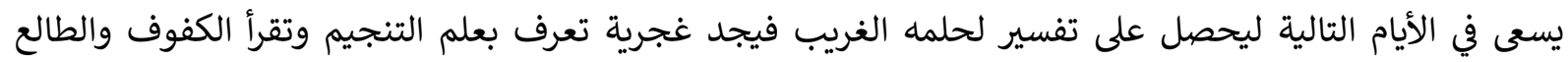

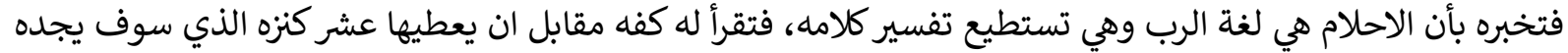

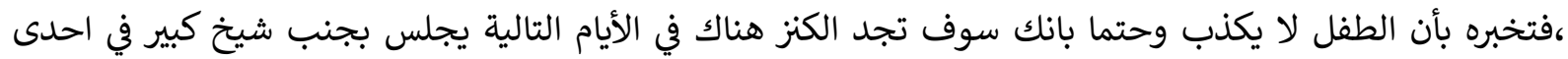

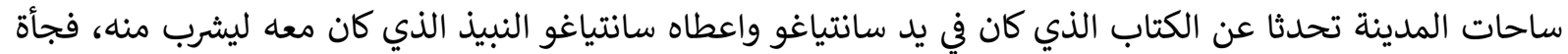

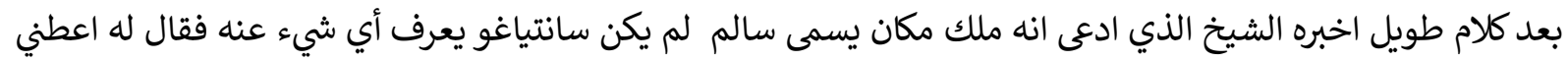




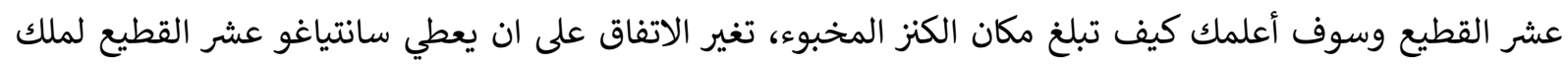

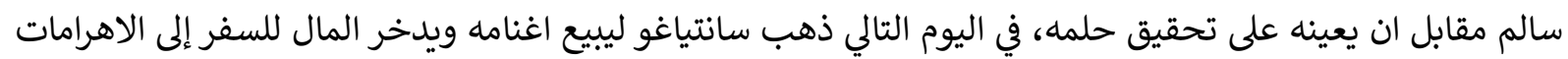

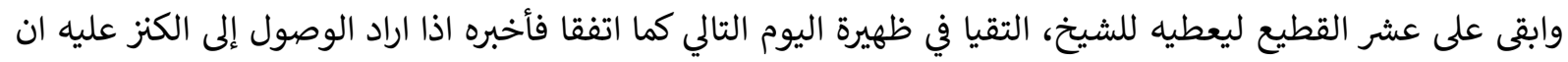

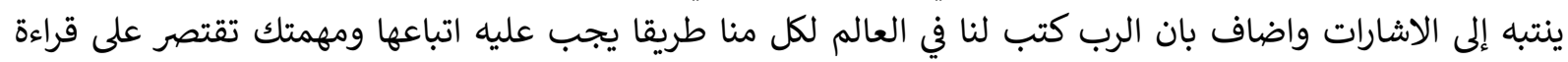

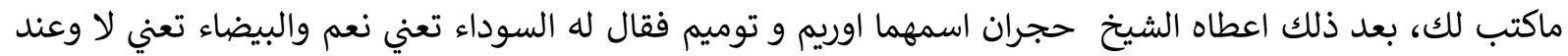

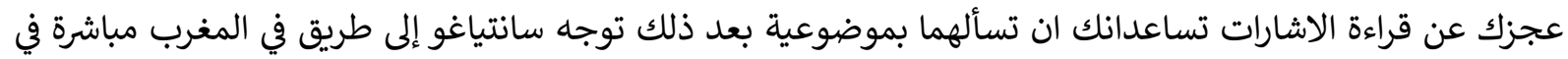

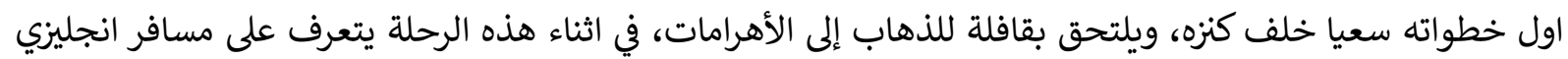

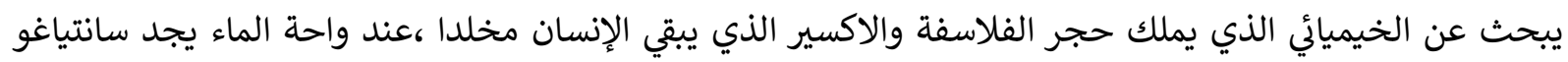

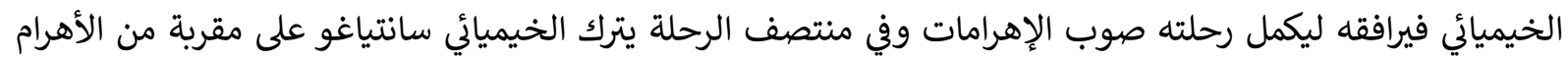

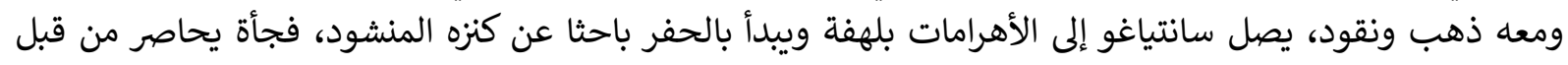

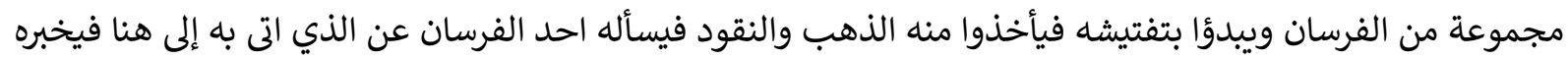

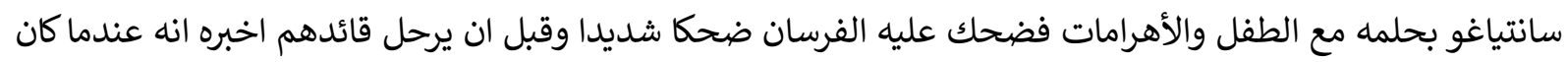

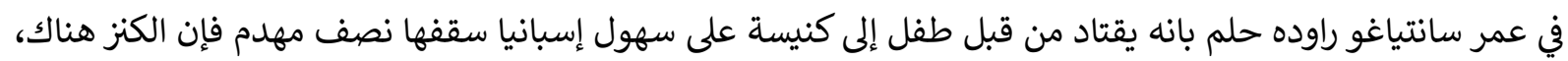

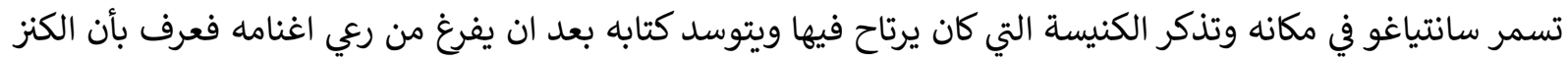

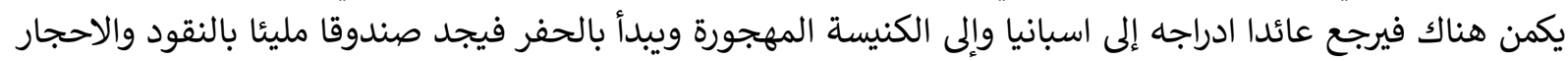
الكريمة عرف بأن الكنز كان تحته ولم يكن الكن يعلم.

\section{الفصل الأول}

\section{أنواع المكان ( التقاطبات المكانية )}

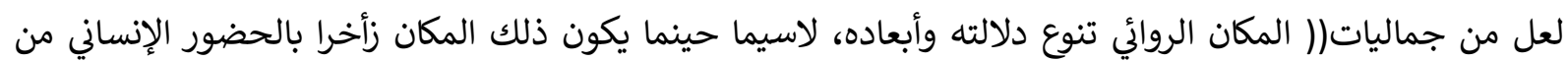

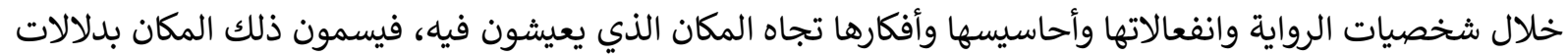

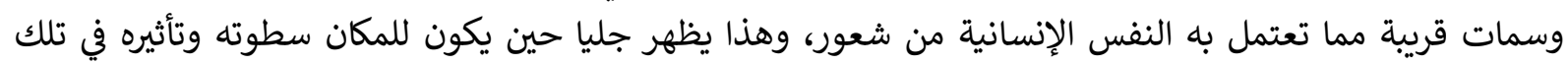

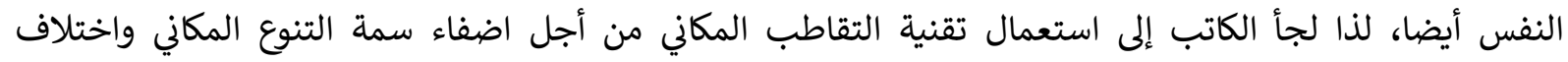

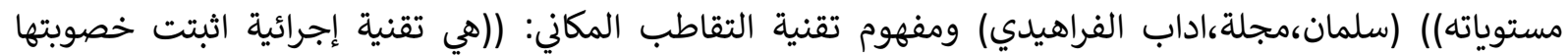

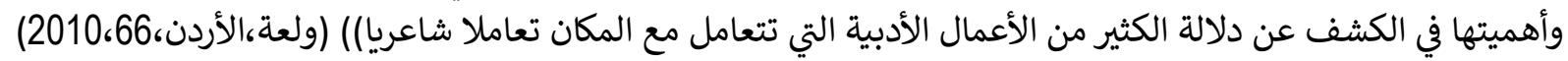

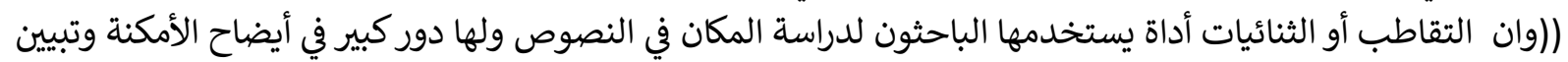

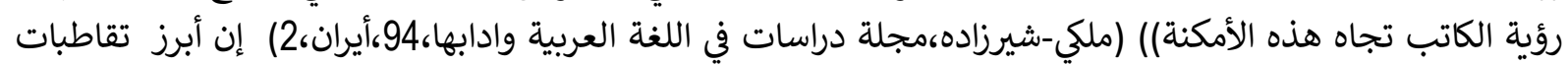

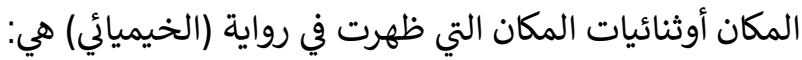

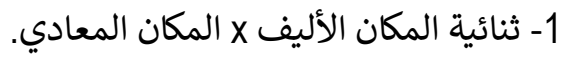

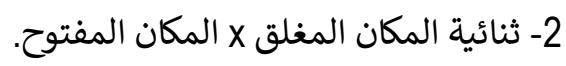

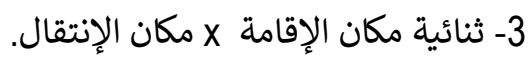

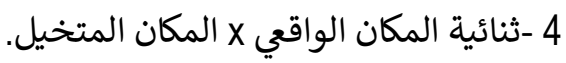

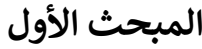

\section{المكان الأليف x المكان المعادي}

المكان الأليف ((هو المكان الذي نألفه ونشعر فيه بالراحة والأمان والأحاسيس الأيجابية، وفيه يمارس الإنسان حياته

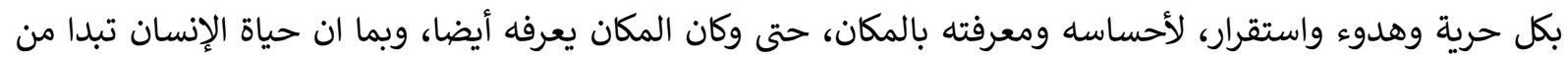

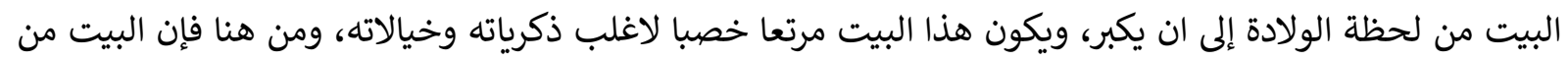

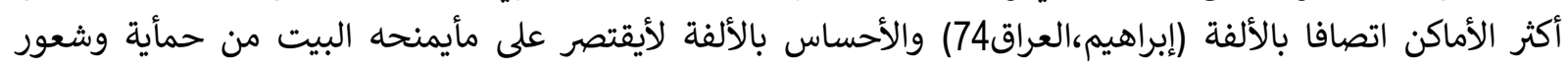


بالدفء، بل يشمل|( الأمكنة كلها بشرط ان يتعود الشعور بالألفة تجاهها، لان المكان ماهو إلا نظام لوجود الأشياء

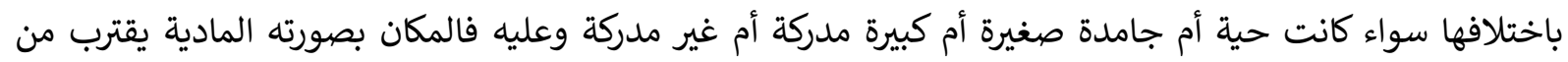

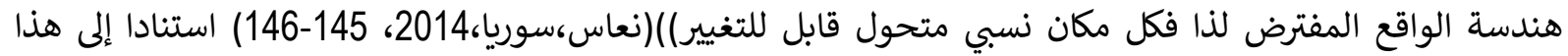

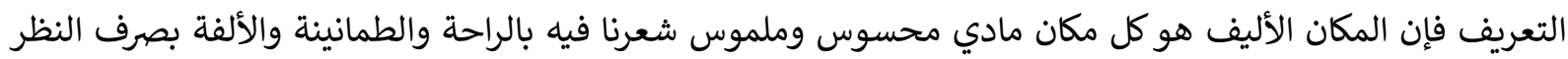
عن كونه بيتا أو مقهى أو حقا شارعا أو فضاء الماء واسعا.

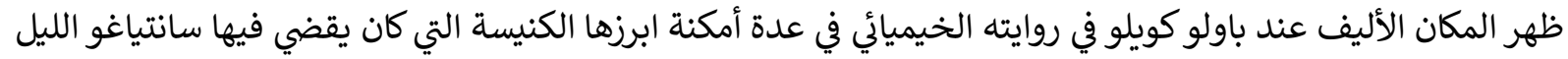

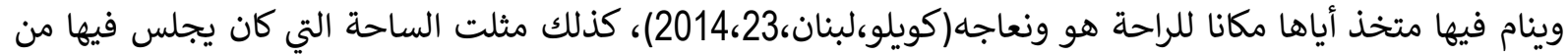

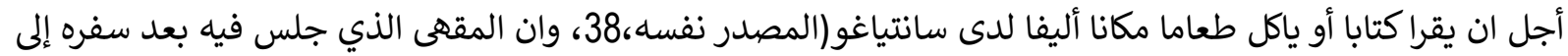

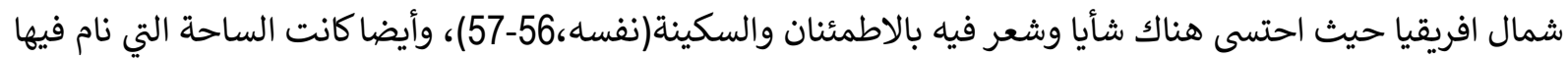

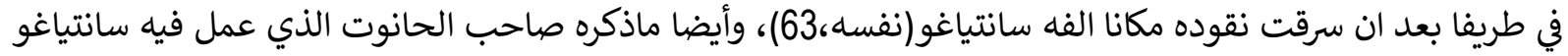

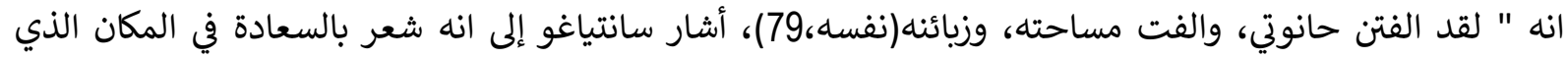

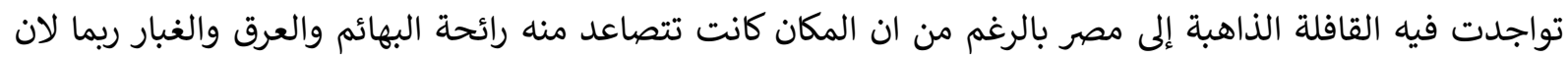

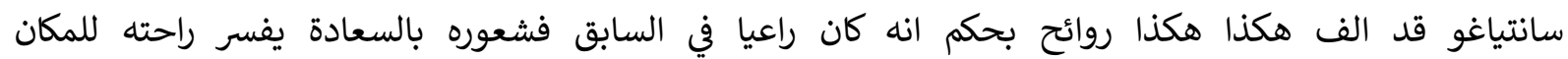

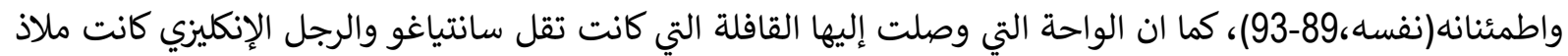

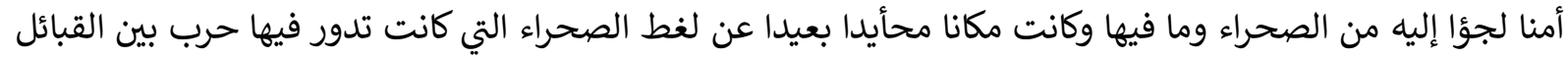

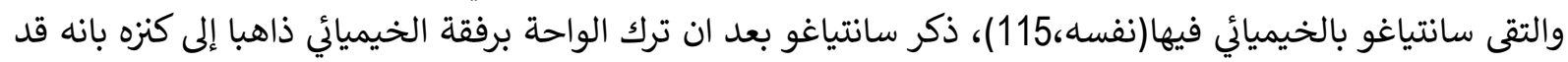

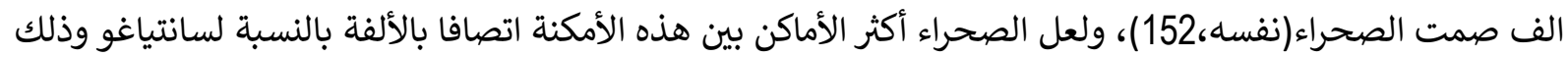

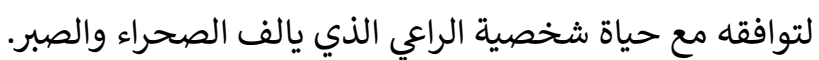

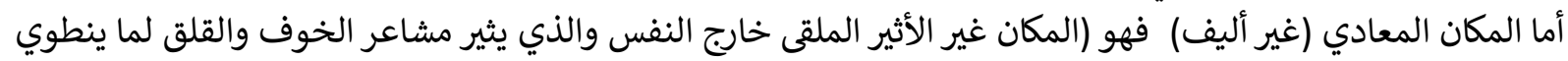

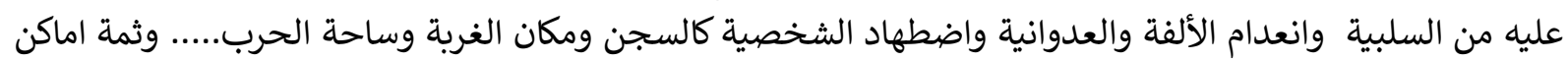

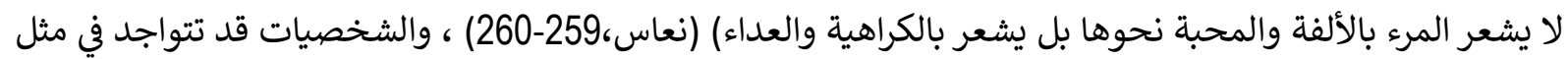

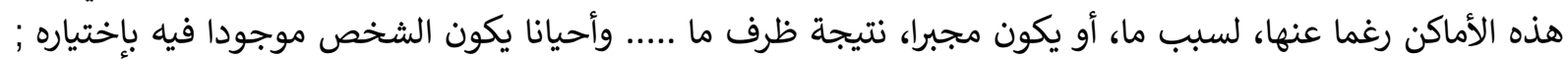

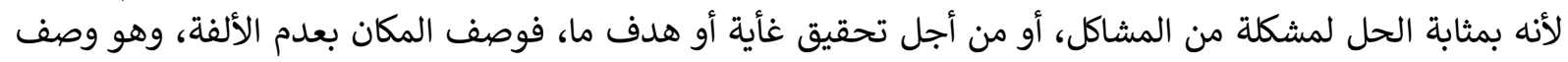

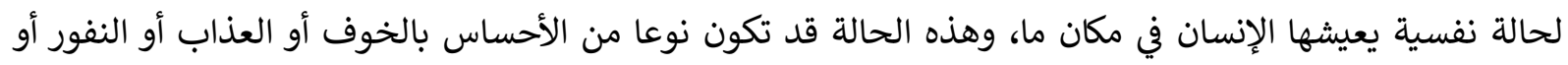

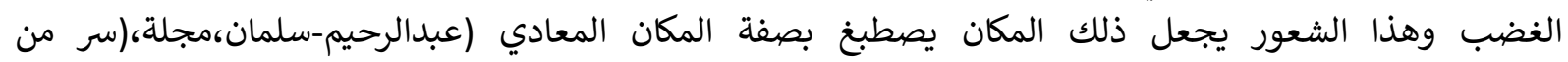

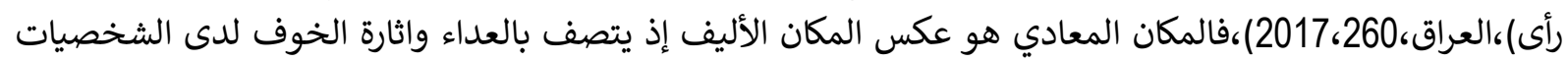
والأحداث وقد ينزعج الإنسان من تواجده فيه ولا يطيقه وقد يسبب له ذكريات حزينة أو مأساوية تبعث على النه النفور والخوف منه. ظهر هذا النوع من الأمكنة عندما ذهب سانتياغو مع الغجرية العجوز إلى بيتها واقتادته إلى إحدى الغرف فشرعت أندا

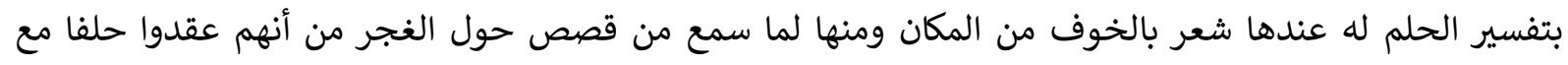

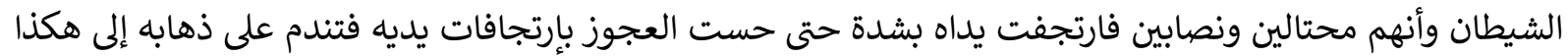

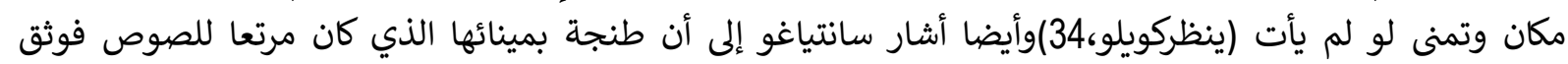

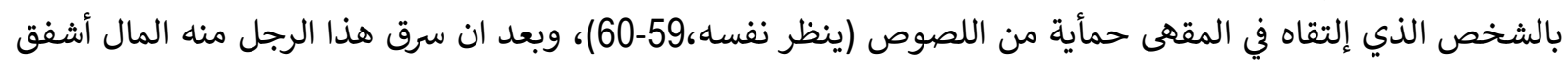

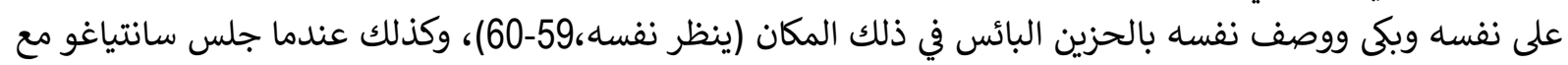

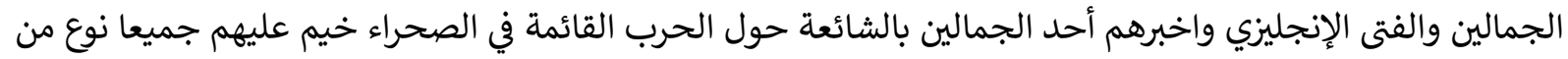

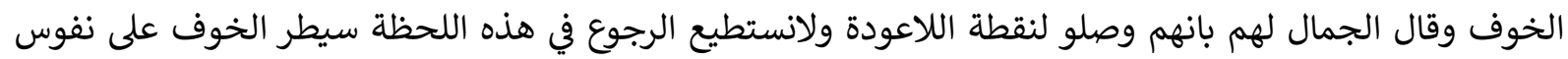

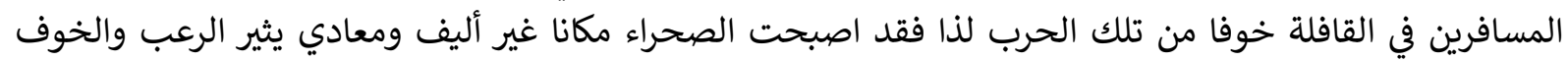

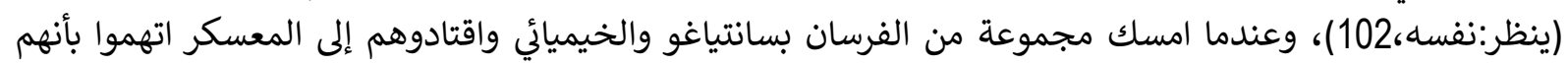


جواسيس وربما سيقتلون ولكن جازف سانتياغو بحياته وقال لهم بأنه سوف يتحول إلى ريح وإن لم يتحول سيقدمان

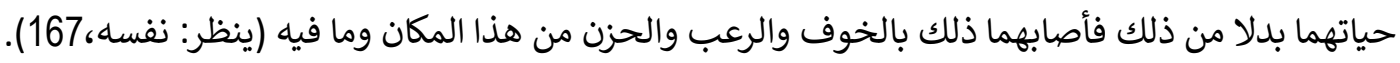

المبحث الثاني

\section{المكان المفتوح × المكان المغلق}

المكان المفتوح هو ذلك ((المكان الذي يظهر من خلال فضاء المدينة المفتوح،بساحاتها وشوارعها وبساتينها ومقاهيها،

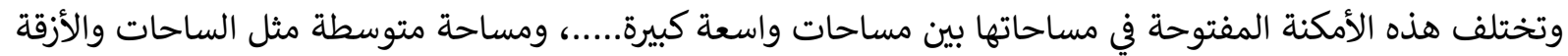

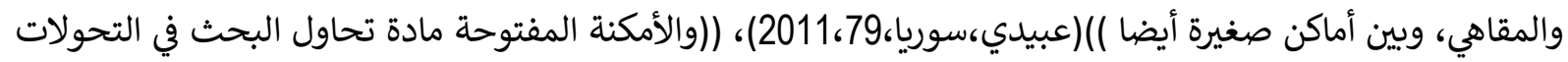

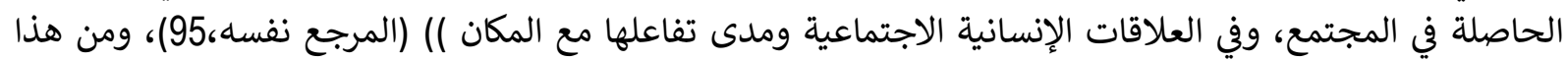

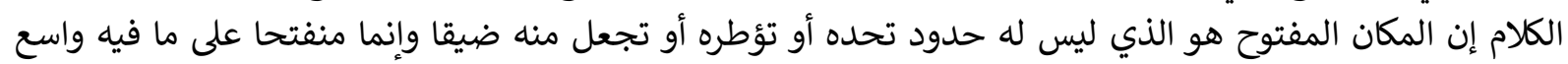

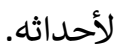
ظهر هذا النوع من الأمكنة بدأية في اسبانيا التي دارت فيها بدأية الأحداث في الرواية فظهرت أنها مكانا مفتوحا من وأنا

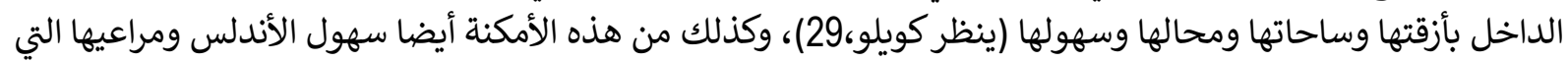

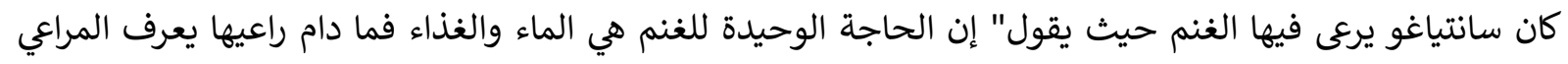

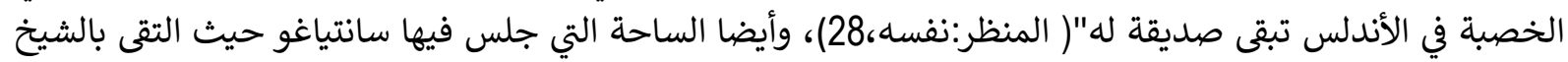

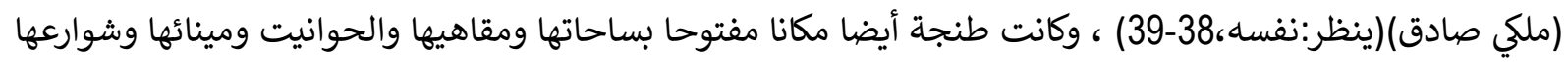

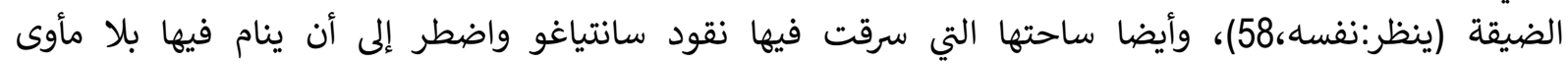

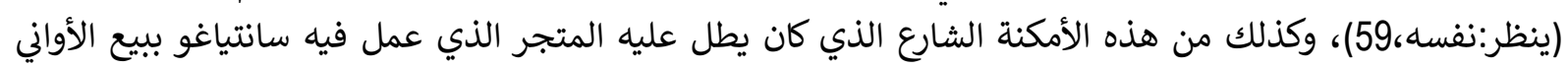

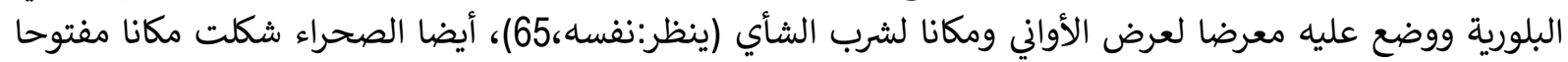

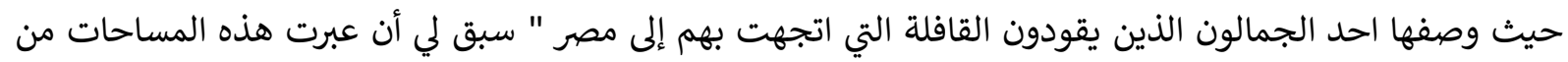

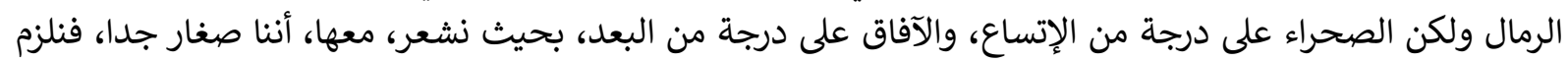

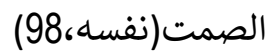

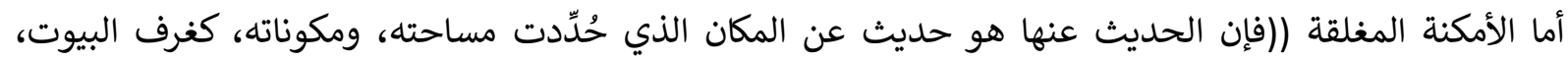

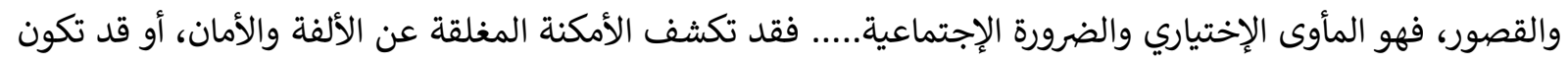

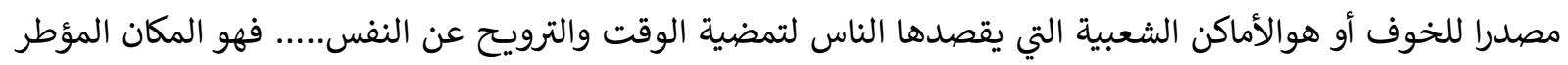

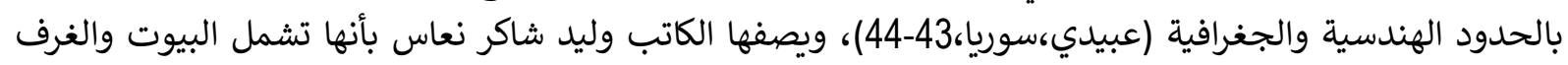

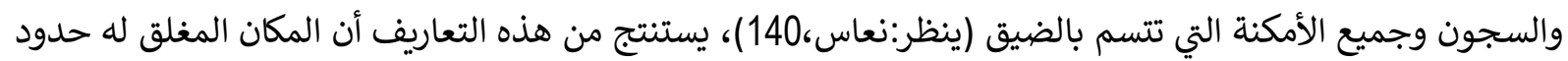

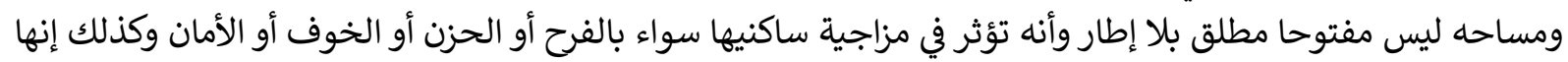

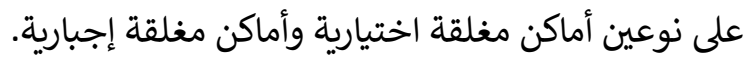

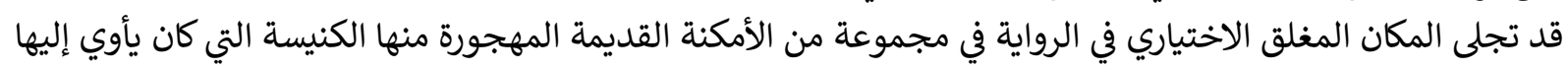

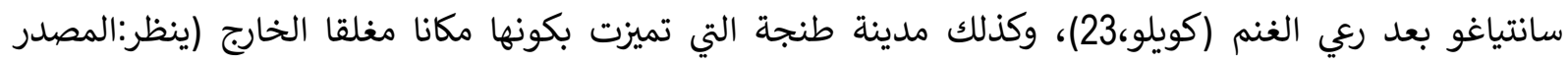

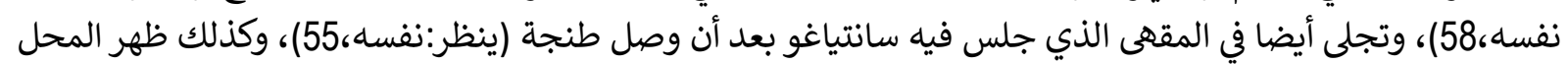

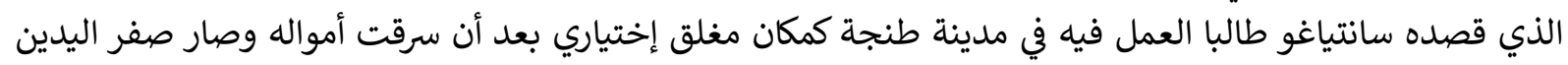

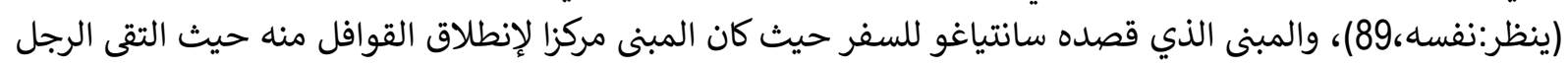

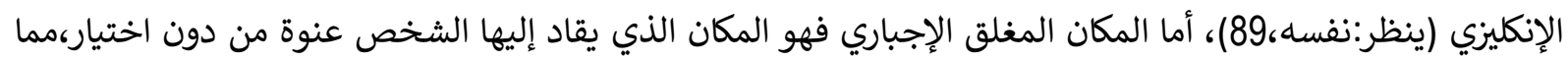

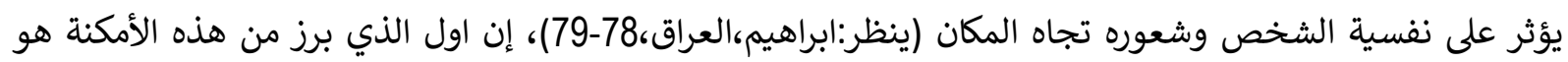

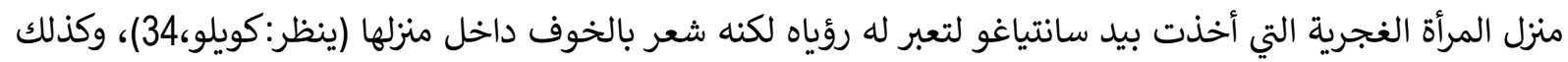

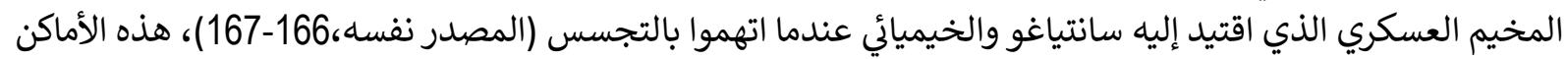

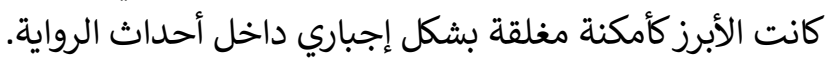


International Journal of Education and Language Studies

المبحث الثالث

مكان الإقامة × مكان الانتقال

تغلب على بعض الاماكن صفة الاقامة بغض النظر عن كون الاقامة اختيارية أو اجبارية،واماكن الاقامة لاتقتصر على البيت وانما قد تشمل القرية والمدينة.

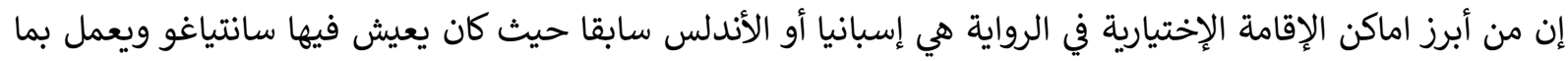

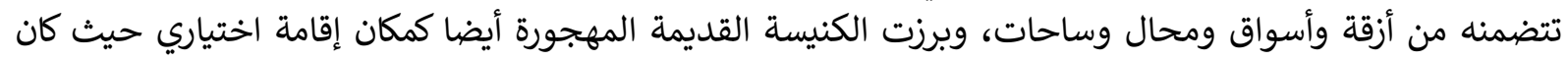

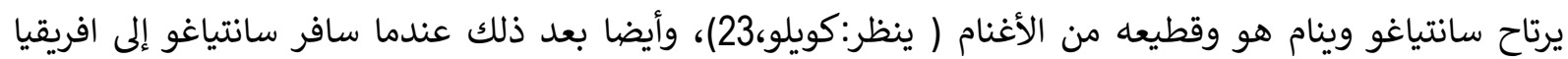

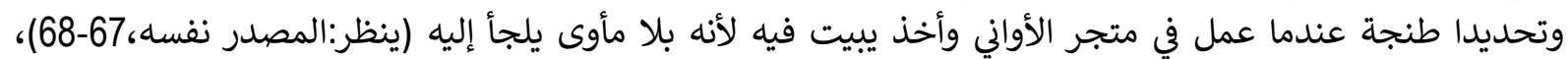

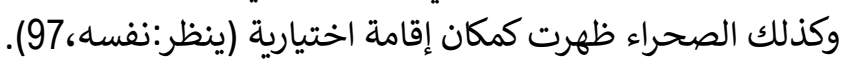

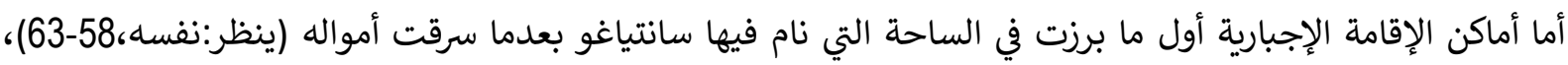

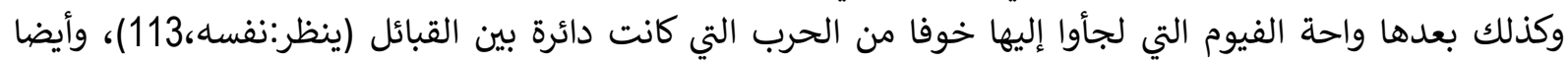

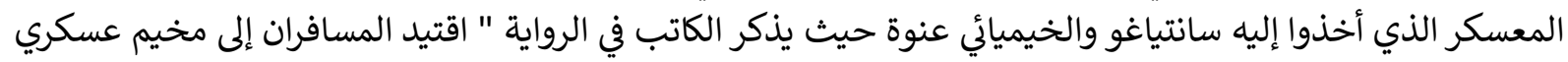

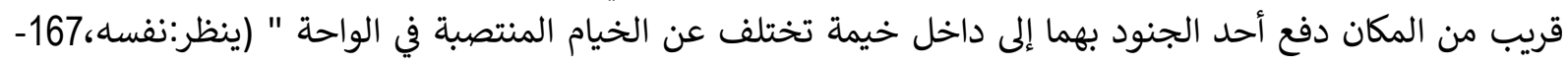

هذا أبرز ما جاء في الرواية من أمكنة إقامة سواء اختيارية أو إجبارية.

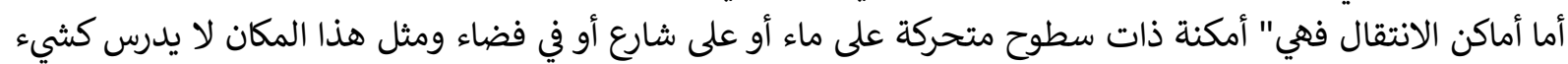

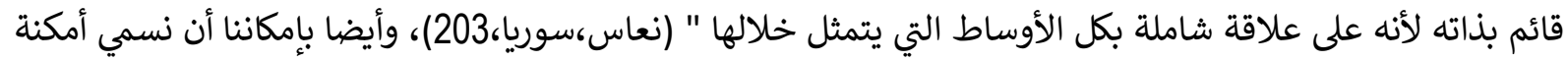

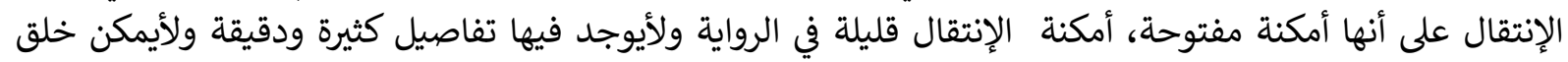

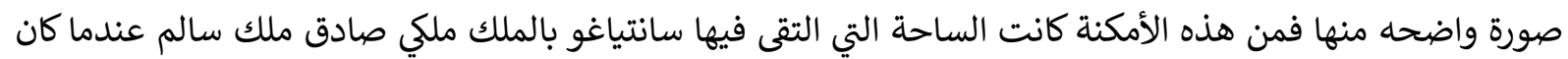

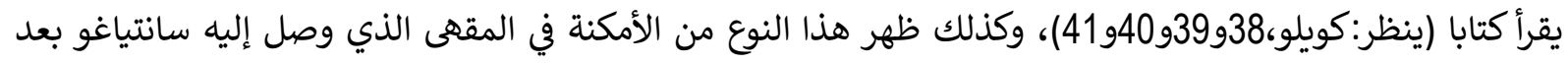

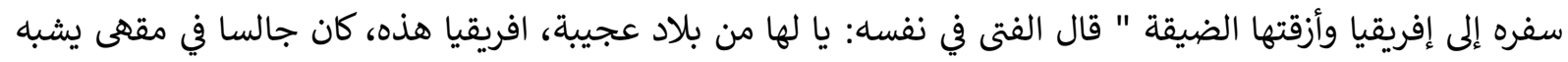

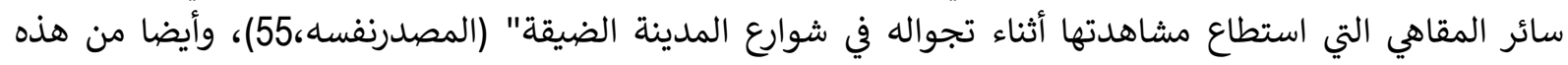

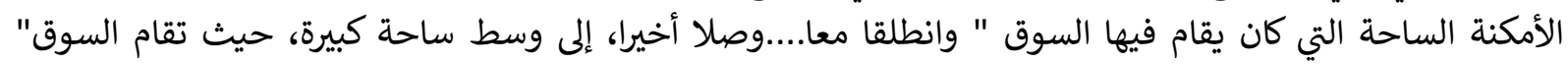

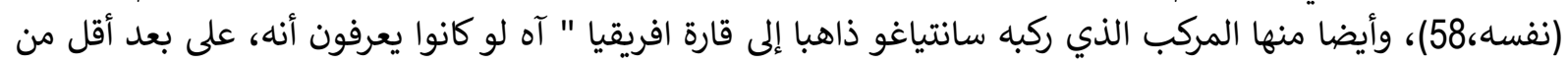

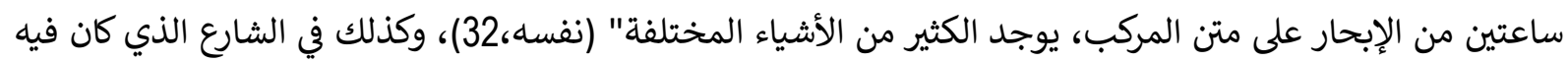

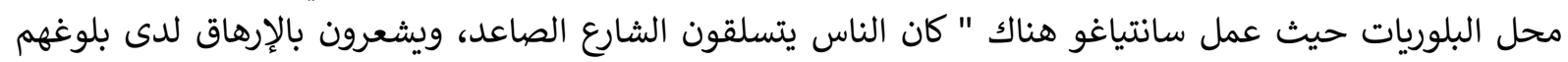

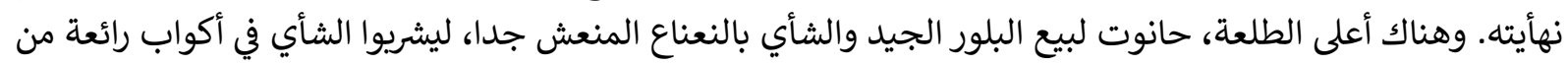

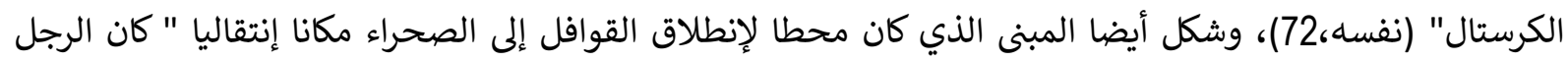

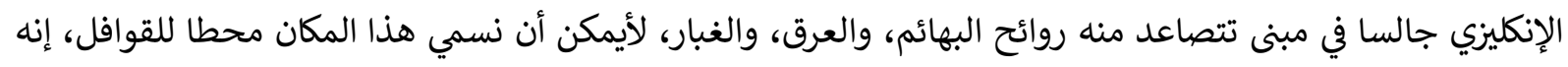

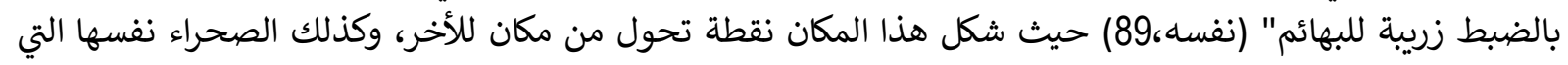

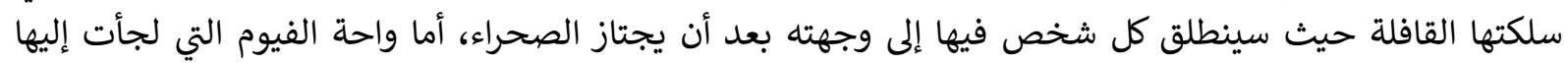

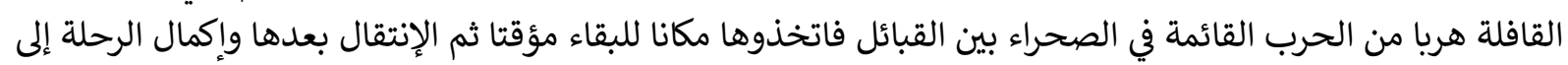

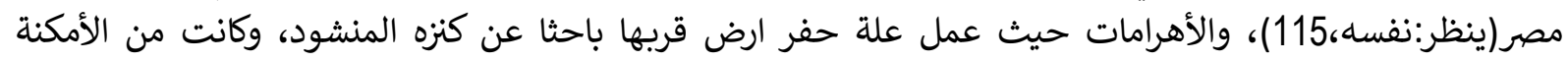

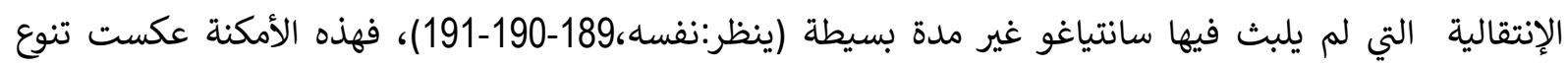

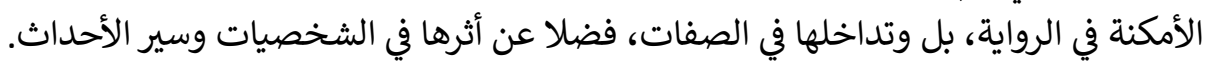




\section{المكان الواقي × المكان المتخيل}

إن المكان الواقعي يمثل المكان الذي توجد له نسخة أو مثيل في واقع الكاتب والقارئ أو المتلقي وقد تكون واقعاق واقعية المكان

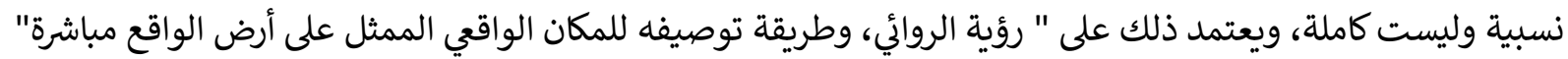

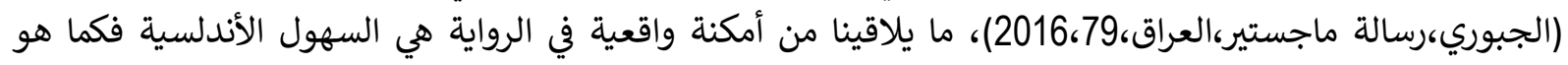

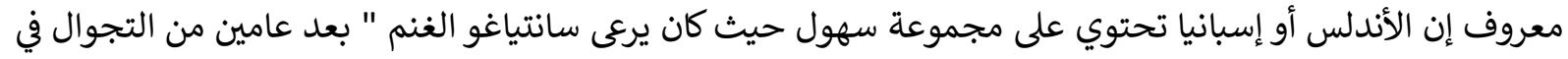

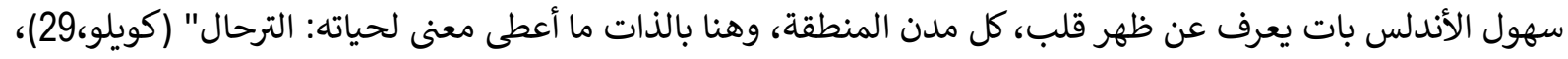

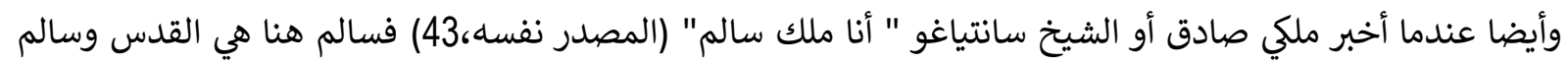

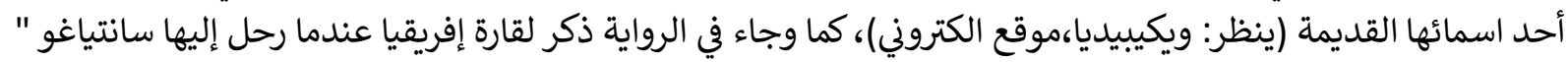

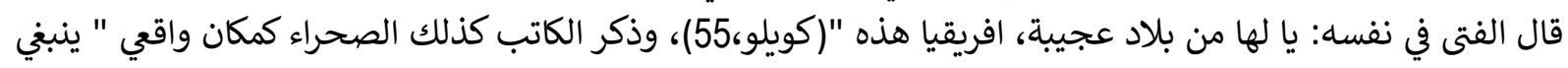

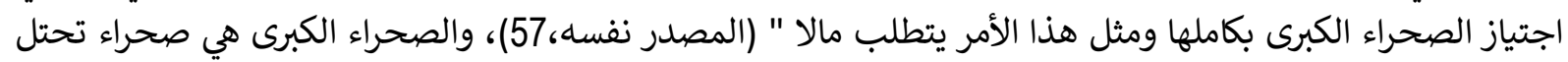

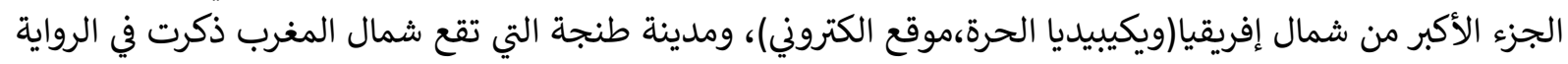

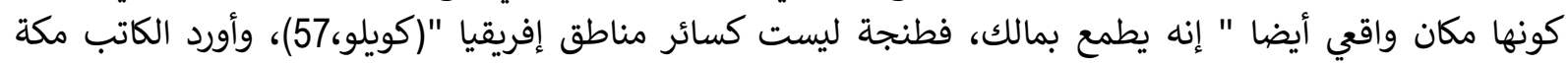

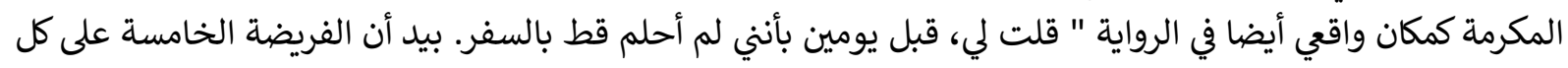

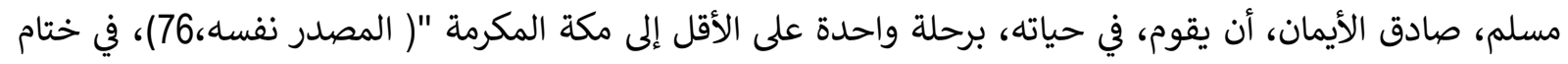

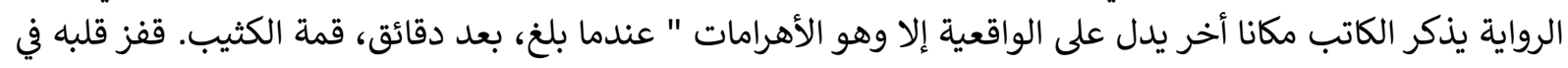

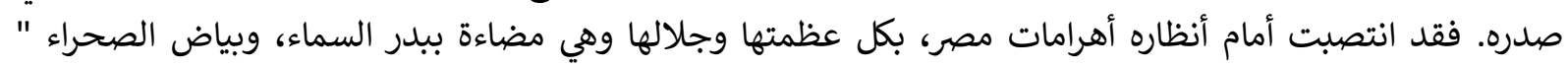

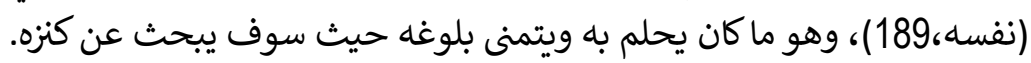

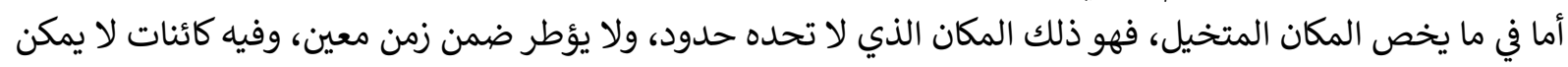

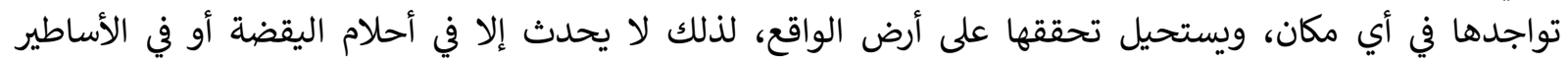

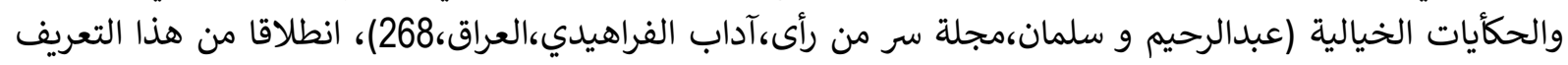

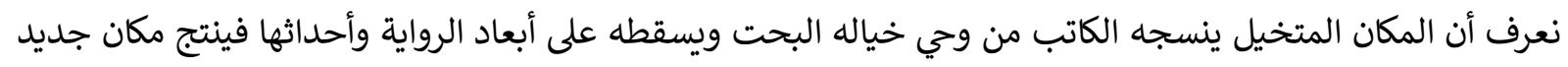

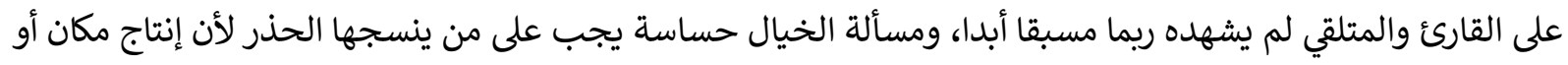

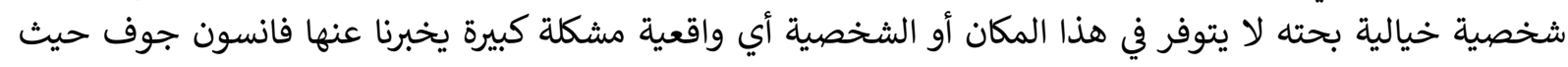

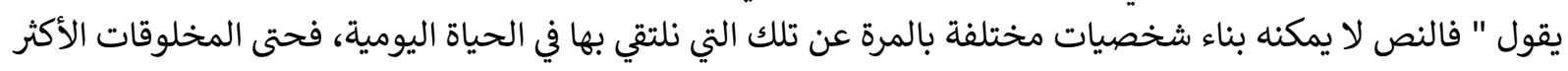

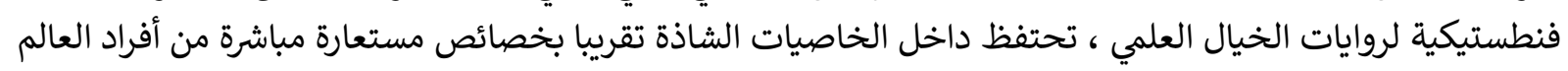

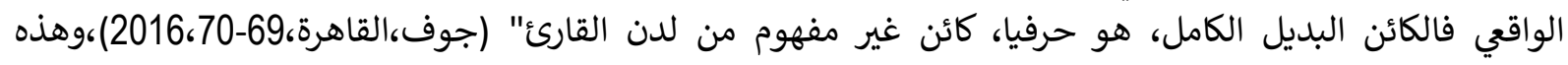

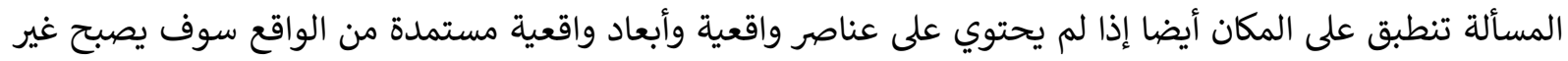

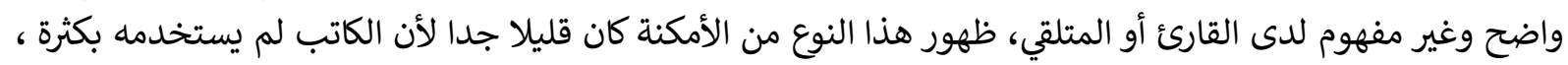

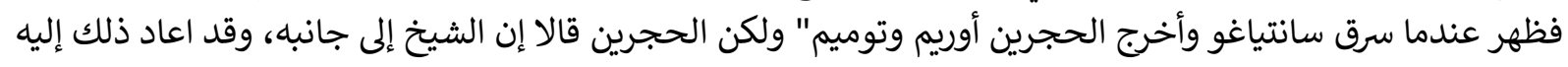

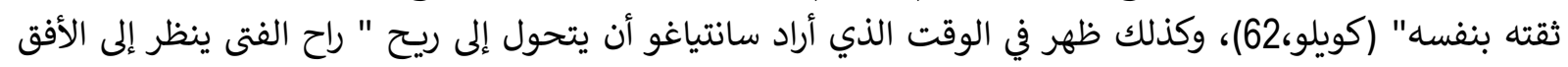

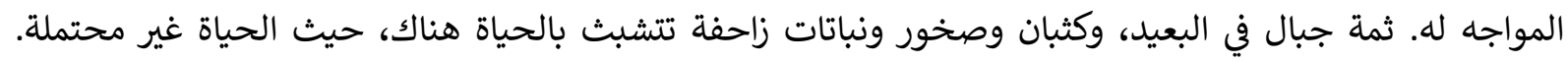

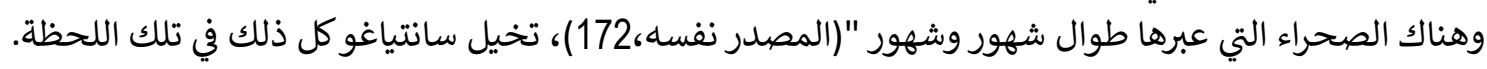

الوصف

يقول قدامة ابن جعفر في كتابه نقد الشعر متحدثا عن معنى الوصف " انما هو ذكر الشيء كما فيه من الأحوال والهيئات

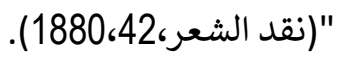

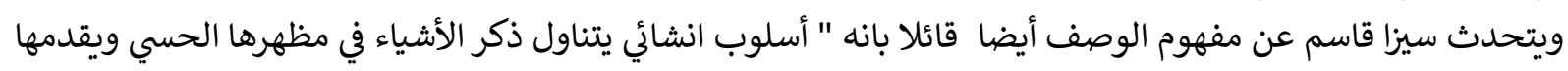

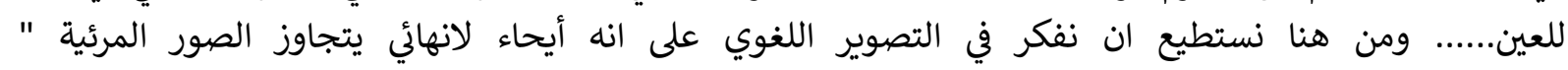

(قاسم،القاهرة، (2004،111). 


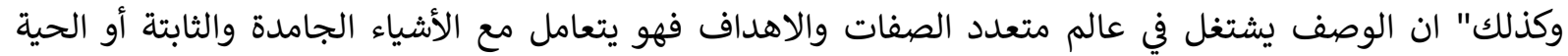

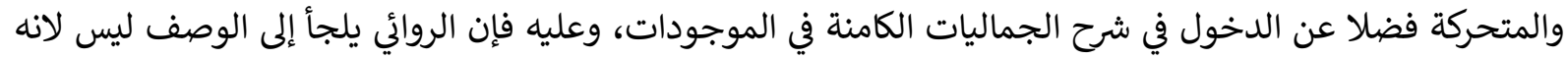

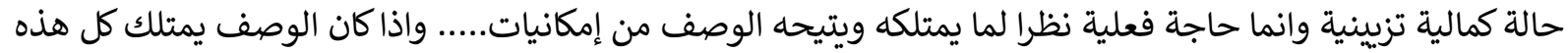

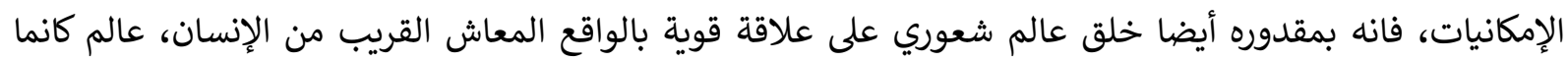

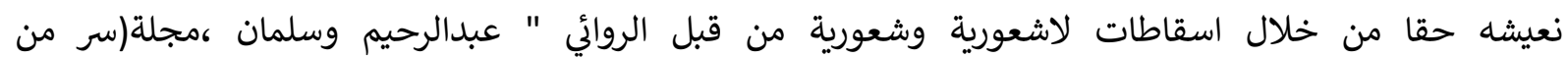

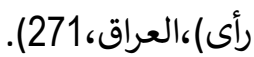

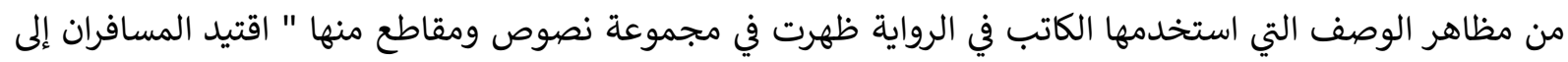

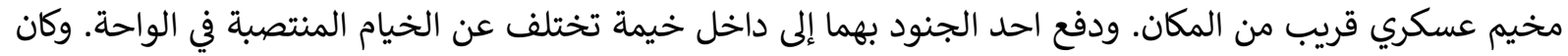

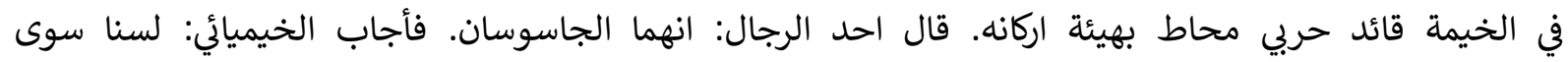

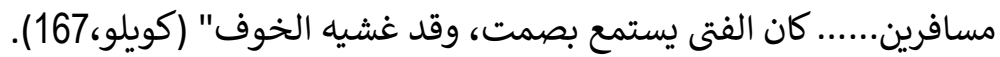
استخدام الكاتب لتقنيات الوصف أظهرت كمية الخوف التي كان يشعر بها سانتياغو ومدى إنى تاثير المكان على الشخصية الروائية وظهور ذلك الحب بشكل بارز عليها.

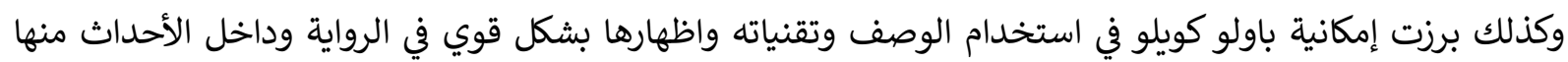

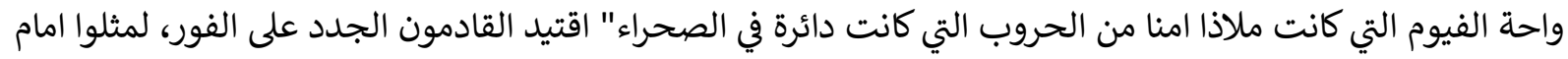

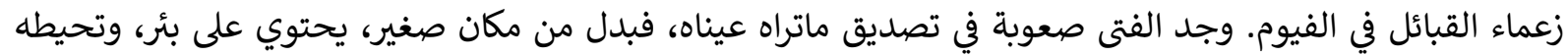

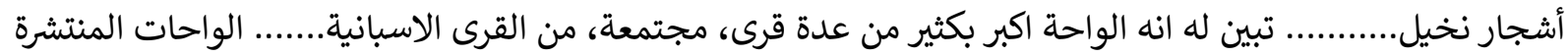

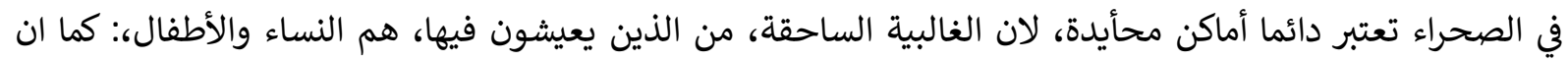

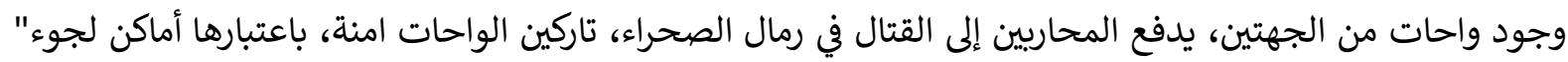

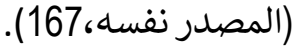

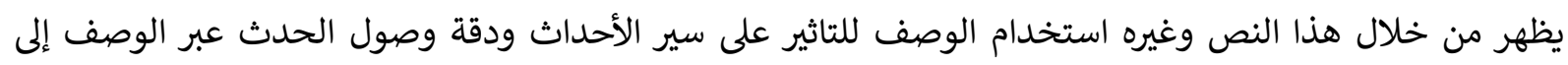

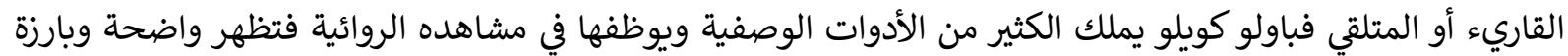
على الأحداث والأشخاص.

المبحث الأول

\section{علاقة المكان بالشخصية}

إن علاقة أي مكان بأي شخص تعتمد على مدى التفاعل بين الطرفين والذوبان في بعضهما البعض من خلئل خلال الانعكاسات

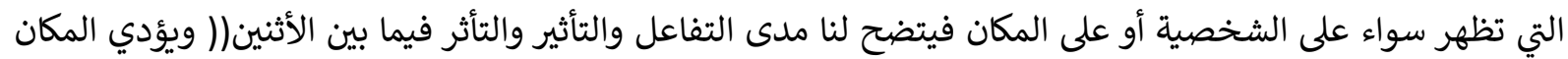

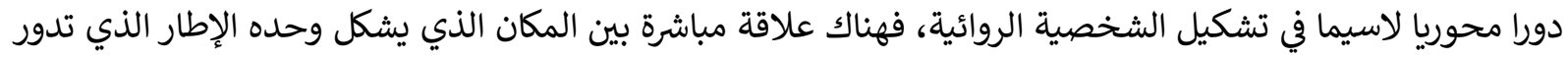

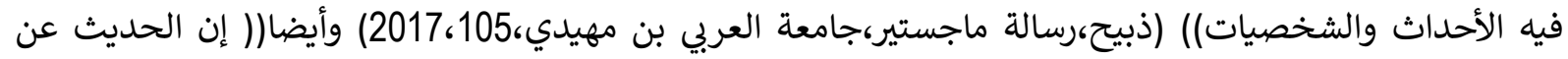

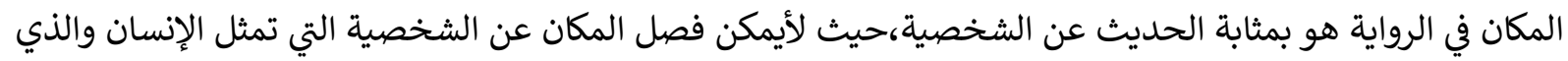

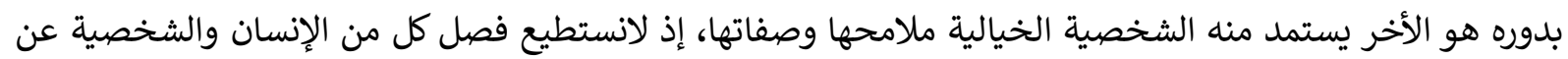

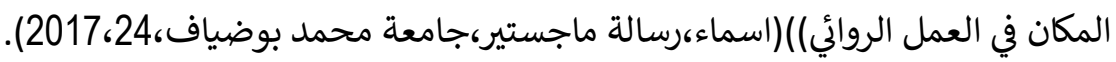

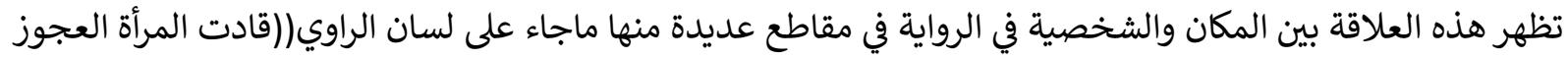

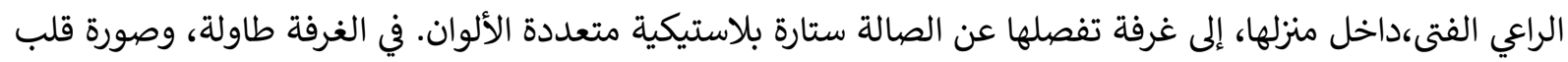

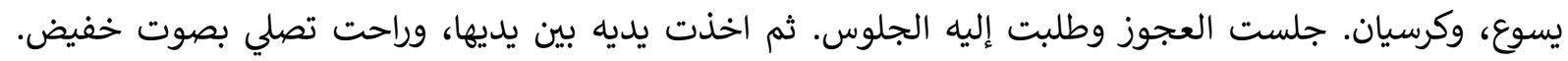

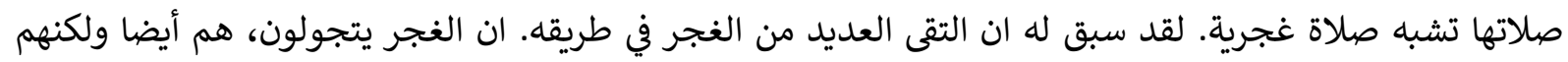

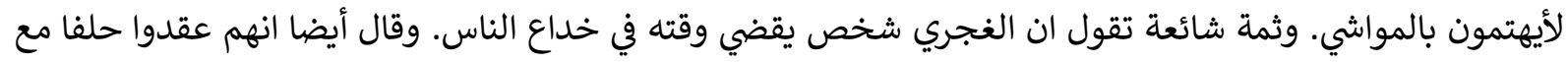

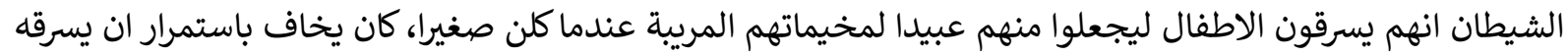




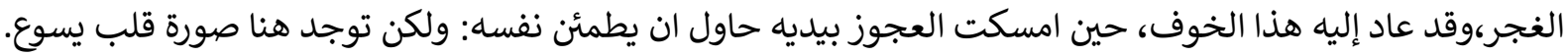

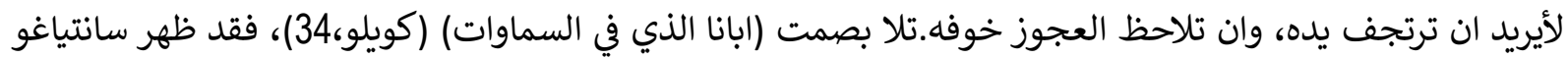

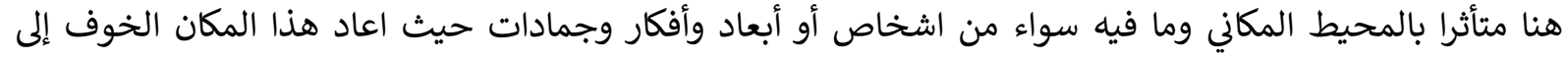

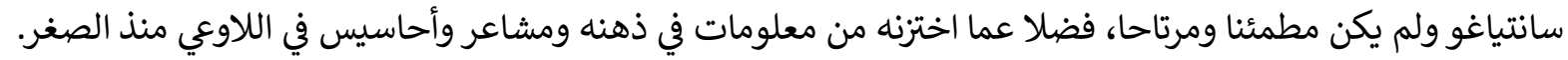

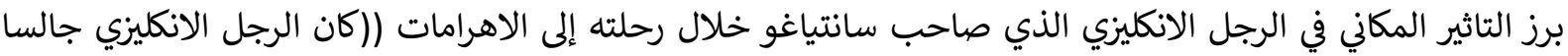

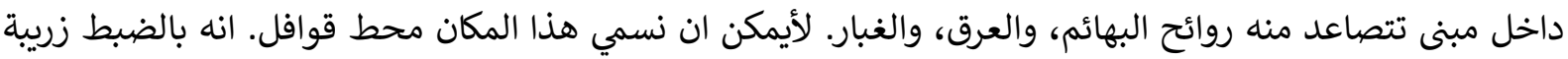

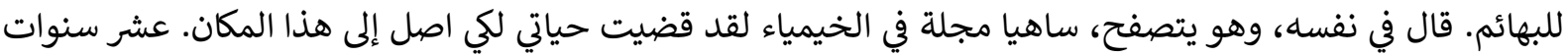
من التحصيل ساقتني إلى زريبة للبهائم)) (المصدر نفسه،،

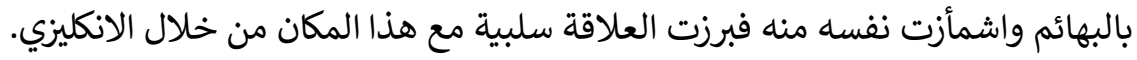

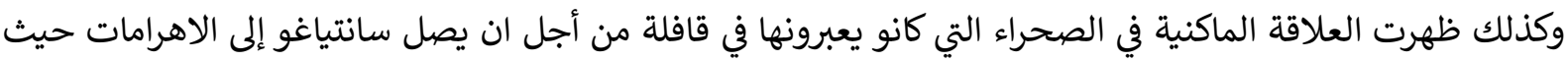

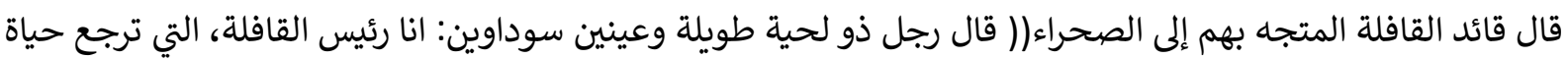

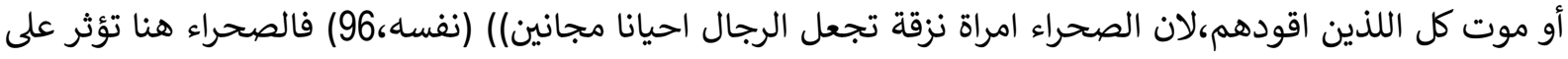

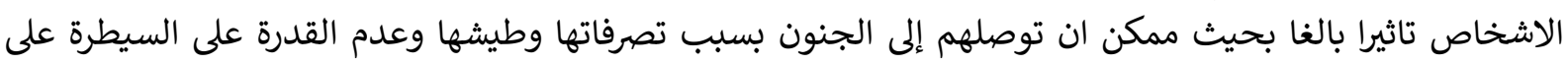

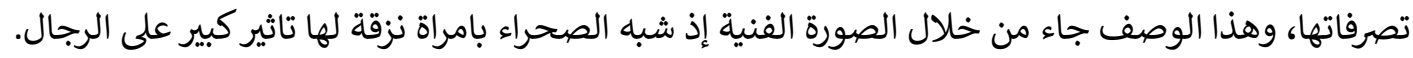

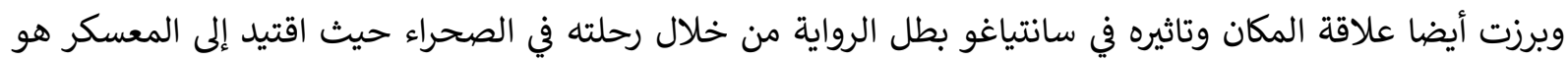

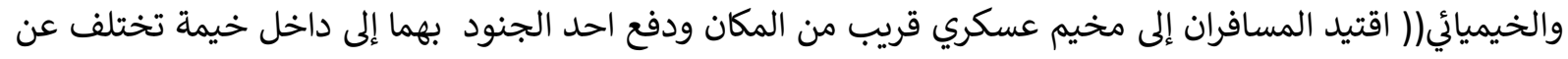

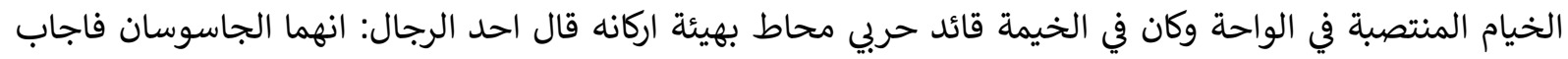

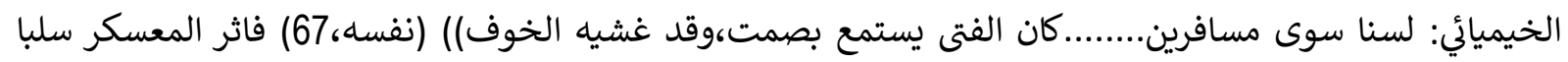

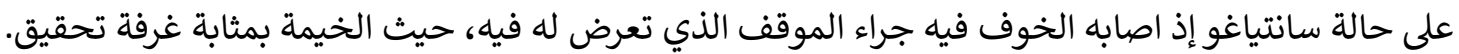

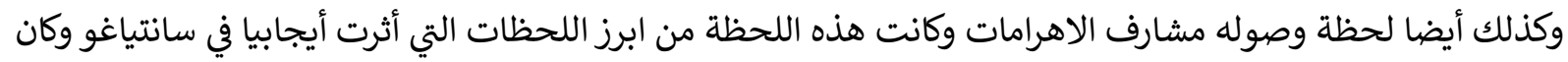

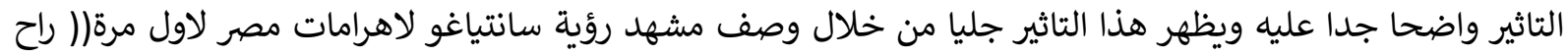

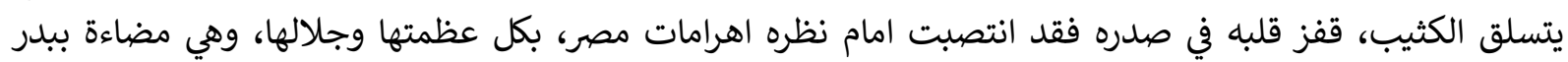

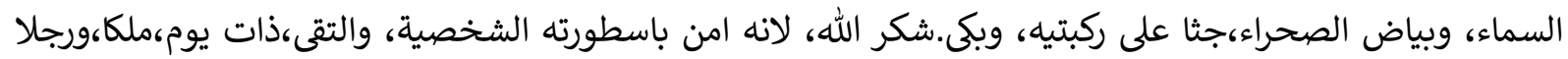

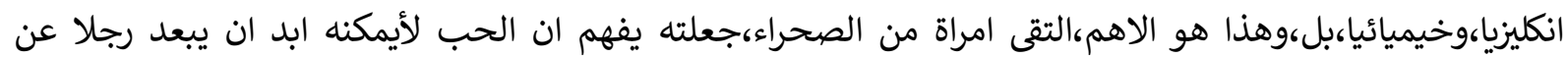

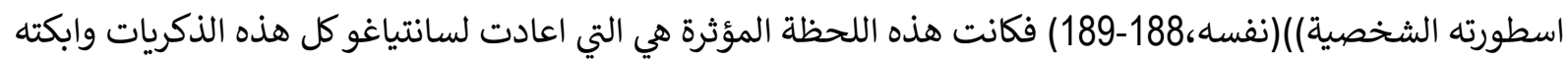

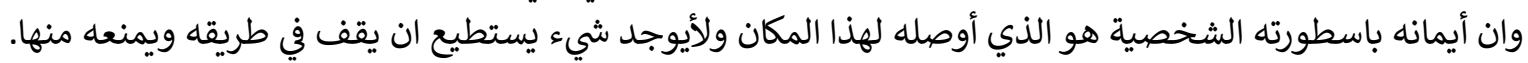

علاقة المكان بالحدث

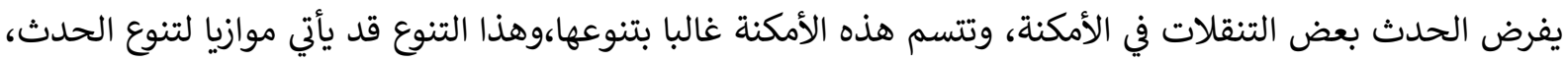

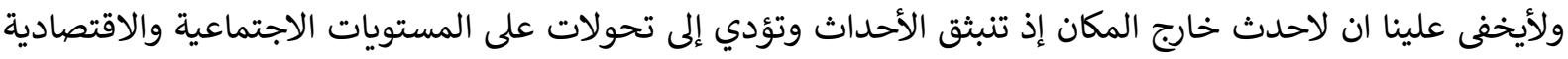

$$
\text { والسياسية(عبيدي،217). }
$$

عند استعراضنا لأحداث رواية (الخيميائي) لباولو كويلو، نجد انها تتوزع في أماكن متعددة في الطبيعة كالسهول في

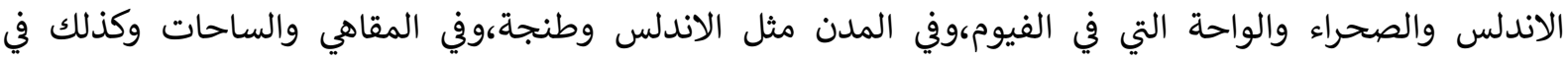

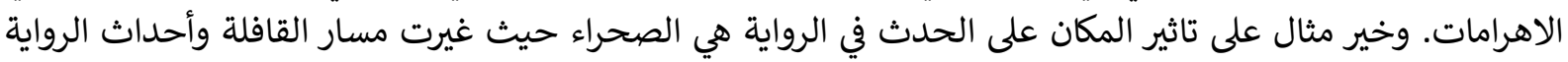

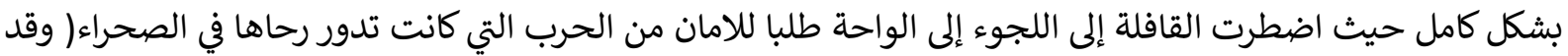

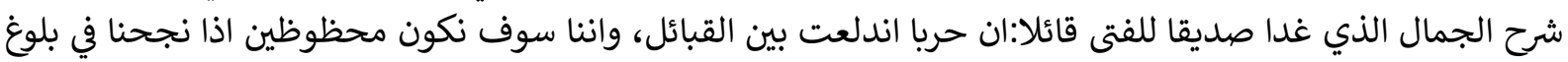
الواحة)(كويلو،110). كذلك الاهرامات في مصر التي سعى إليها سانتياغو منذ بدأية أحداث الرانيات الرواية والرؤية التي رآها كانت تشير إلى الاهرامات

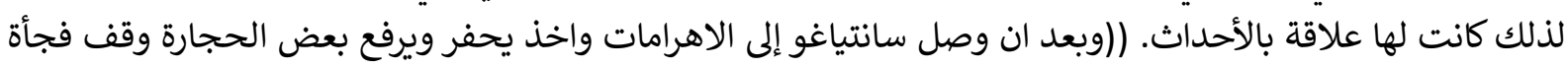

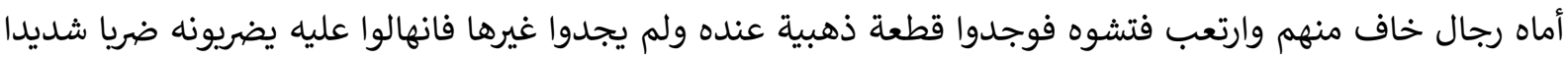

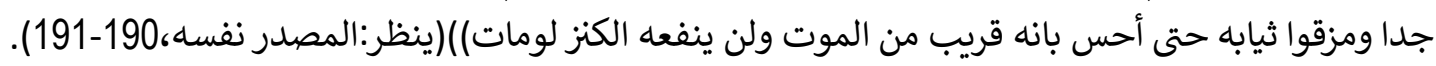




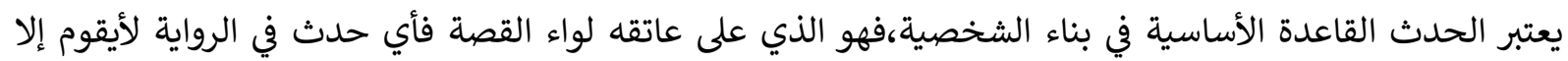

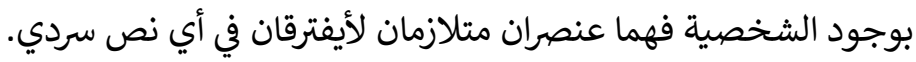

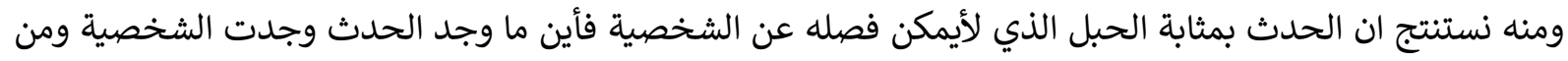

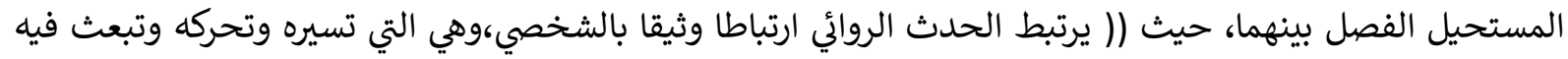

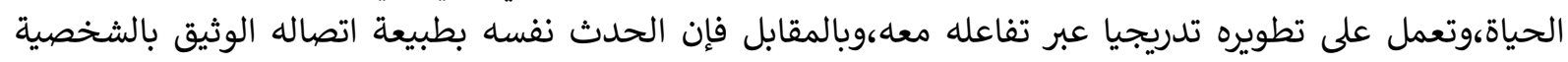

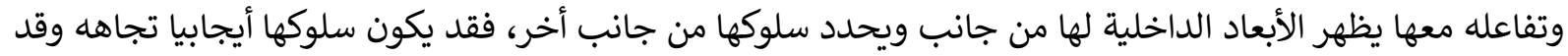

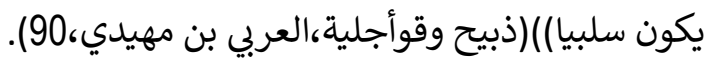

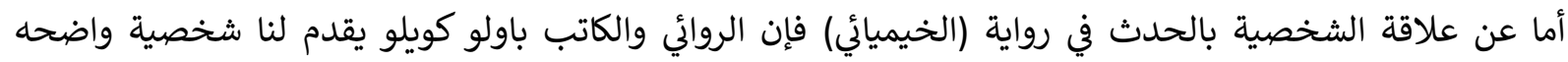

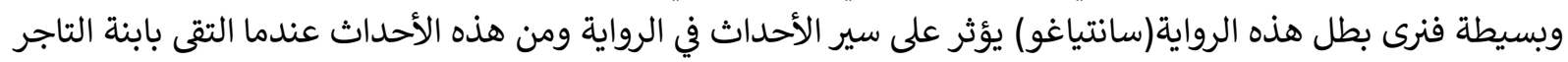

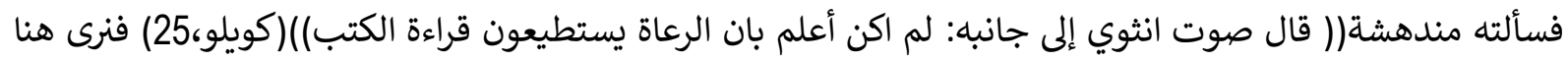

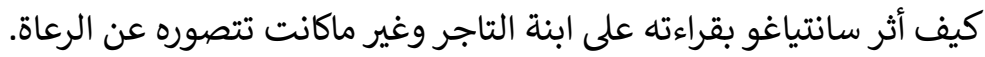

\section{قائمة المصادر والمراجع}

أولا: الكتب:

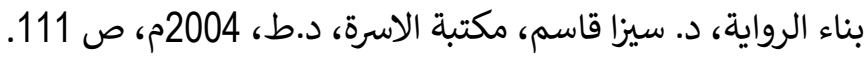

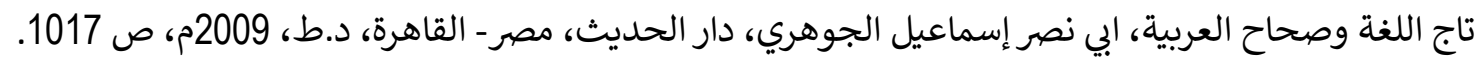

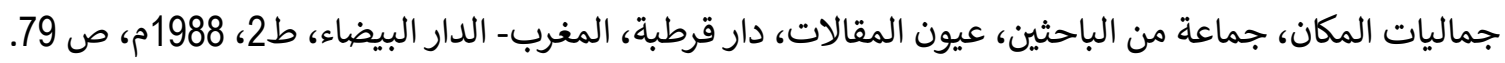

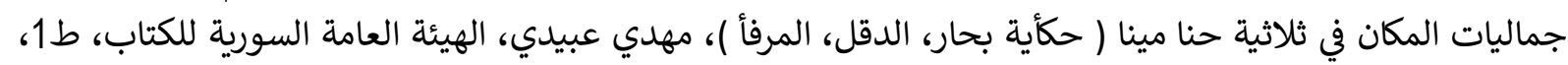

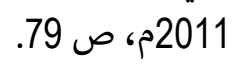

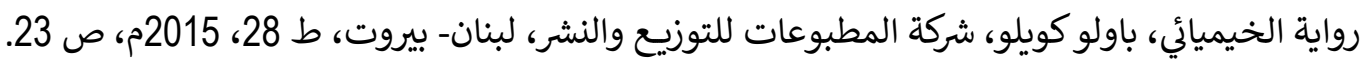

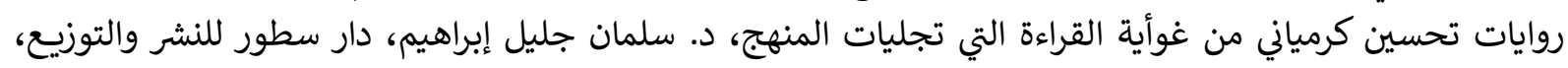

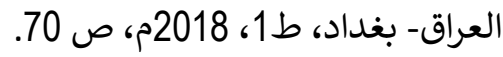

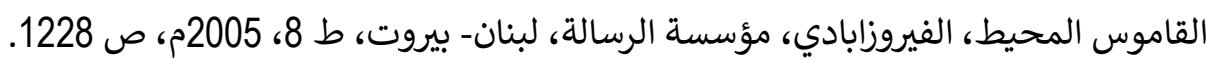

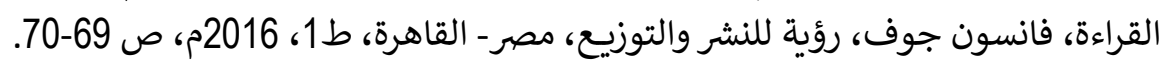

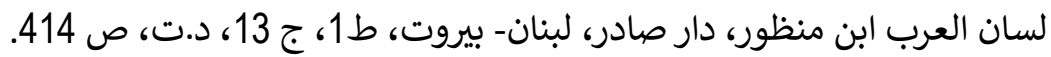

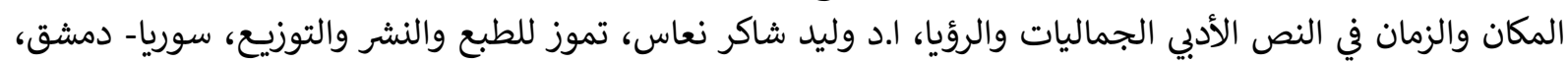

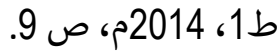
المكان ودلالته في رواية مدن الملح لعبد الرحمن منيف، صالح ولعة، عالم الكتب الحديث للنشر والتوزيع، الأردن- اربد،

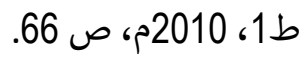
نقد الشعر، قدامة بن جعفر، مطبعة الجوائب، القسطنطينية، ط1، 1081، 1801م، ص 42. ثانيا: الدوريات: التقاطب المكاني في رواية أولاد إليهودية، ا.م.د سلوى جرجيس سلمان، دار سطور، العراق- بغداد، ط1، 2018م، ص 
جماليات المكان في رواية أخر الملائكة فاضل العزاوي نموذجا، بحث، د. سنان عبدالعزيز عبدالرحيم- د. سلوى

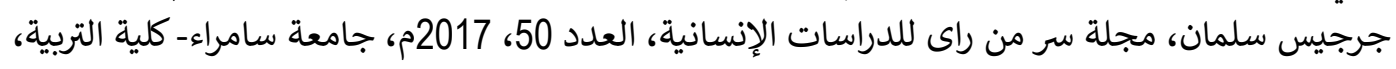

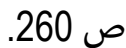

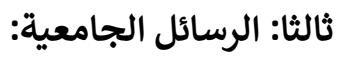

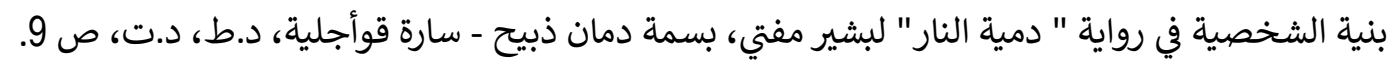

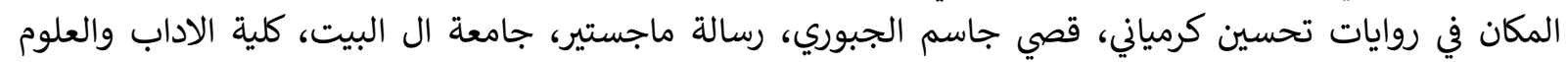

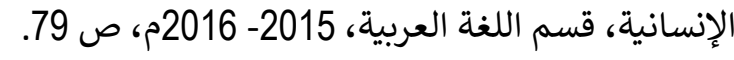

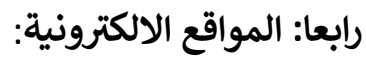
ويكيبيديا الموسوعة الحرة www.wikipedia.com. 